OPEN ACCESS

Edited by:

$\mathrm{Bo} \mathrm{Yu}$,

Institute of Microbiology (CAS), China

Reviewed by:

Yejun Han,

University of Chinese Academy of

Sciences, China

Sofia Maina,

Agricultural University of Athens,

Greece

*Correspondence:

Xianrui Chen

chenxianrui123@126.com

Mengxue Diao

mengxuediao@gxas.cn

${ }^{+}$These authors have contributed equally to this work and share first

authorship

Specialty section: This article was submitted to Industrial Biotechnology,

a section of the journal Frontiers in Bioengineering and

Biotechnology

Received: 09 October 2021 Accepted: 06 December 2021

Published: 25 January 2022

Citation:

Li J, Lu J, Ma Z, Li J, Chen X, Diao M and Xie N (2022) A Green Route for High-Yield Production of Tetramethylpyrazine From Non-Food

Raw Materials.

Front. Bioeng. Biotechnol. 9:792023.

doi: 10.3389/fbioe.2021.792023

\section{A Green Route for High-Yield Production of Tetramethylpyrazine From Non-Food Raw Materials}

\author{
Jing $\mathrm{Li}^{1 \dagger}$, Jian $\mathrm{Lu}^{1 \dagger}$, Zhilin $\mathrm{Ma}^{1 \dagger}$, Jianxiu $\mathrm{Li}^{2}$, Xianrui Chen ${ }^{2 *}$, Mengxue $\mathrm{Diao}^{2 *}$ and \\ Nengzhong Xie ${ }^{2}$
}

${ }^{1}$ Life Science and Technology College, State Key Laboratory for Conservation and Utilization of Subtropical Agro-bioresources, Guangxi University, Nanning, Guangxi, China, ${ }^{2}$ State Key Laboratory of Non-food Biomass and Enzyme Technology, National Engineering Research Center for Non-food Biorefinery, Guangxi Biomass Engineering Technology Research Center, Guangxi Key Laboratory of Biorefinery, Guangxi Academy of Sciences, Nanning, Guangxi, China

2,3,5,6-Tetramethylpyrazine (TMP) is an active pharmaceutical ingredient originally isolated from Ligusticum wallichii for curing cardiovascular and cerebrovascular diseases and is widely used as a popular flavoring additive in the food industry. Hence, there is a great interest in developing new strategies to produce this high-value compound in an ecological and economical way. Herein, a cost-competitive combinational approach was proposed to accomplish green and high-efficiency production of TMP. First, microbial cell factories were constructed to produce acetoin (3-hydroxy-2-butanone, AC), an endogenous precursor of TMP, by introducing a biosynthesis pathway coupled with an intracellular $\mathrm{NAD}^{+}$regeneration system to the wild-type Escherichia coli. To further improve the production of $(R)-A C$, the metabolic pathways of by-products were impaired or blocked stepwise by gene manipulation, resulting in $40.84 \mathrm{~g} / \mathrm{L}(R)-\mathrm{AC}$ with a high optical purity of $99.42 \%$ in shake flasks. Thereafter, an optimal strain designated GXASR11 was used to convert the hydrolysates of inexpensive feedstocks into $(R)$-AC and achieved a titer of $86.04 \mathrm{~g} / \mathrm{L}$ within $48 \mathrm{~h}$ in a 5 - $\mathrm{L}$ fermenter under optimized fermentation conditions. To the best of our knowledge, this is the highest $(R)$ - $\mathrm{AC}$ production with high optical purity $(\geq 98 \%)$ produced from non-food raw materials using recombinant $E$. coli. The supernatant of fermentation broth was mixed with diammonium phosphate (DAP) to make a total volume of $20 \mathrm{ml}$ and transferred to a high-pressure microreactor. Finally, $56.72 \mathrm{~g} / \mathrm{L}$ TMP was obtained in $3 \mathrm{~h}$ via the condensation reaction with a high conversion rate (85.30\%) under optimal reaction conditions. These results demonstrated a green and sustainable approach to efficiently produce high-valued TMP, which realized value addition of low-cost renewables.

Keywords: tetramethylpyrazine, non-food raw materials, synthetic biology, acetoin, metabolic engineering, green process

\section{INTRODUCTION}

2,3,5,6-Tetramethylpyrazine (TMP), also known as ligustrazine, is a biologically active alkaloid, which occurs naturally in the rhizome of a Chinese traditional medicinal herb, Chuanxiong (Ligusticum wallichii) (Xiao et al., 2006; Chen et al., 2018). TMP is a colorless compound with pleasant roasted, nutty flavor characteristics, and is usually used as a flavor additive in the food and 
TABLE 1 | Summary of studies on TMP production from different carbon and nitrogen sources.

\begin{tabular}{|c|c|c|c|c|c|}
\hline Microorganisms & Carbon sources & Nitrogen sources & $\begin{array}{c}\text { Source of } \\
\text { ammonium ion }\end{array}$ & $\begin{array}{l}\text { TMP } \\
\text { (g/L) }\end{array}$ & References \\
\hline B. amyloliquefaciens XJB-104 & Wheat bran, distiller's grains & Soybean meal & Amino acid & 1.28 & $\begin{array}{l}\text { Zhang et al. } \\
(2019)\end{array}$ \\
\hline B. coagulans CICC 20138 & Glucose & Yeast extract & DAP & 2.54 & $\begin{array}{l}\text { Zhong et al. } \\
\text { (2020a) }\end{array}$ \\
\hline B. licheniformis BL1 (Engineered) & Glucose & Tryptone, yeast extract & $\mathrm{ND}^{\mathrm{a}}$ & 44.77 & Meng et al. (2016) \\
\hline B. licheniformis BLC (Engineered) & Glucose, acetaldehyde & Tryptone, yeast extract & ND & 47.26 & Meng et al. (2020) \\
\hline B. subtilis BJ3-2 & Adlay & Adlay & ND & $6.93^{b}$ & Wen et al. (2020) \\
\hline B. subtilis BS2 & Glucose & Tryptone, yeast extract & ND & 29.70 & Meng et al. (2015) \\
\hline B. subtilis CICC 10211 & Glucose & Yeast extract, tryptone & DAP & 8.34 & Xiao et al. (2014) \\
\hline B. subtilis CICC 20030 & $\begin{array}{l}\text { Rapeseed meal, glucose, } \\
\text { wheat bran }\end{array}$ & Rapeseed meal, wheat bran & Amino acids & 0.49 & Hao et al. (2020) \\
\hline B. subtilis CCTCC M 208,157 & Glucose & Wheat bran & DAP & $3.01^{b}$ & Hao et al. (2013) \\
\hline B. subtilis CCTCC M 208,157 & Glucose & Yeast extract & DAP & 7.43 & $\begin{array}{l}\text { Zhu and Xu } \\
(2010 b)\end{array}$ \\
\hline B. subtilis ССТCC M 208,157 & Glucose & Fish peptone, yeast extract & DAP & 7.46 & $\begin{array}{l}\text { Zhu and Xu } \\
\text { (2010a) }\end{array}$ \\
\hline B. subtilis IFO 3013 & Glucose, AC & Soybean peptone & Amino acid & $2.50^{b}$ & $\begin{array}{l}\text { Besson et al. } \\
(1997)\end{array}$ \\
\hline B. subtilis IFO 3013 & Soybean, acetoin & Soybean & L-Threonin & 0.53 & $\begin{array}{l}\text { Larroche et al. } \\
\text { (1999) }\end{array}$ \\
\hline B. subtilis LB5 & Glucose & Yeast extract, peptone & ND & 10.69 & Yin et al. (2018) \\
\hline B. subtilis XZ1124 & Glucose & Yeast extract, peptone & DAP & 4.20 & Zhu et al. (2010) \\
\hline Bacillus sp. RX3-17 & Glucose & Soytone & DAP & 4.33 & Xiao et al. (2006) \\
\hline Corynebacterium glutamicum MB-1923 & Glucose & Urea, N-Z-amine & $\begin{array}{l}\text { DAP, } \\
\text { ammonium sulphate }\end{array}$ & 3.00 & $\begin{array}{l}\text { Demain et al. } \\
(1967)\end{array}$ \\
\hline E. coli BL2 (DE3) (Engineered) & Glucose & Yeast extract & DAP & 16.11 & Xu et al. (2018) \\
\hline E. coli BL2 (DE3) (Engineered) & Acetaldehyde & Yeast extract, peptone & DAP & 94.00 & $\begin{array}{l}\text { Peng et al. } \\
\text { (2020a) }\end{array}$ \\
\hline $\begin{array}{l}\text { Lactococcus lactis subsp. lactis biovar. } \\
\text { diacetylactis FC1 }\end{array}$ & Galactose & Arginine & ND & 0.81 & Kim et al. (1994) \\
\hline Monacus strain M-3 & Starch & Peptone & ND & $13.49^{c}$ & Jia et al. (2017a) \\
\hline Paenibacillus polymyxa CICC 23617 & Glucose, acetoin & Yeast extract & DAP & 14.90 & Xiao et al. (2014) \\
\hline P. polymyxa CICC 23617 & Glucose & Yeast extract & DAP & 3.52 & Xiao et al. (2014) \\
\hline Serratia marcescens CICC 10187 & $\begin{array}{l}\text { Sucrose, corn steep liquor } \\
\text { powder, acetoin }\end{array}$ & $\begin{array}{l}\text { Ammonium citrate, corn steep } \\
\text { liquor powder }\end{array}$ & DAP & 18.97 & Xiao et al. (2014) \\
\hline Saccharomyces Cerevisiae (Engineered) & Corn flour & Corn flour & ND & $10.55^{b}$ & Cui et al. (2020) \\
\hline
\end{tabular}

${ }^{a} N D$, no data

${ }^{\mathrm{b}} \mathrm{g} / \mathrm{kg}$ dry substrate

${ }^{c} \mathrm{mg} / \mathrm{L}$.

beverage industries (Xiao et al., 2014; Xu et al., 2018). More importantly, TMP is beneficial to human health and has been proven to have a variety of pharmacological activities. Many pharmacological studies have confirmed that it can prevent a series of diseases, including cardiovascular and cerebrovascular diseases, ischemic stroke, cancer and diabetes (Cao et al., 2015; Guo et al., 2016). Accordingly, studies on TMP have attracted considerable attention.

Currently, there exist three main approaches for TMP production, including extraction from medicinal plants, chemical synthesis, and biomanufacturing (Müller and Rappert, 2010; Jia et al., 2017a). Previous studies have concluded that TMP is one of the key ingredients of Rhizoma Chuanxiong (RC), however, it presents in trace amounts in RC ranging from lower than $0.10-11.75 \mu \mathrm{g} / \mathrm{g}$ (Huang et al., 2011; Chen et al., 2018; Yin et al., 2018). Therefore, the extraction of natural TMP is costly, inefficient and unsustainable (Zhu et al., 2010; Xiao et al., 2014; Jia et al., 2017a; Peng et al., 2020a). The chemical synthesis approach has become less desirable because of the stringent requirement of environmental protection, the current shortage of fossil fuels, and the consideration of manufacturing costs (Jia et al., 2017a). Compared with direct extraction and chemical synthesis, the bio-based route is more environmentally friendly and costefficient (Meng et al., 2015).

The compound acetoin (3-hydroxy-2-butanone, AC) is an indispensable flavor enhancer widely applied in foods, cosmetics and chemical synthesis (Li et al., 2018; Xiao et al., 2018) and also plays a pivotal role in TMP synthesis as a precursor (Demain et al., 1967; Xiao et al., 2014; Peng et al., 2020a; Zhong et al., 2020a). To improve the AC accumulation in microbial fermentation, various strategies have been employed, including screening of efficient natural producers of acetoin (Xiao et al., 2006; Zhu et al., 2010; Zhang et al., 2011; Yin et al., 2018; Zhong et al., 2020b), metabolic engineering (Vivijs et al., 2014; Xu et al., 2015; Jang et al., 2017; Li et al., 2018; Bae et al., 2021) and fermentation optimization (Xiao et al., 2007; Zhu and Xu 2010a; Zhang et al., 2012; Yuan et al., 2019). 


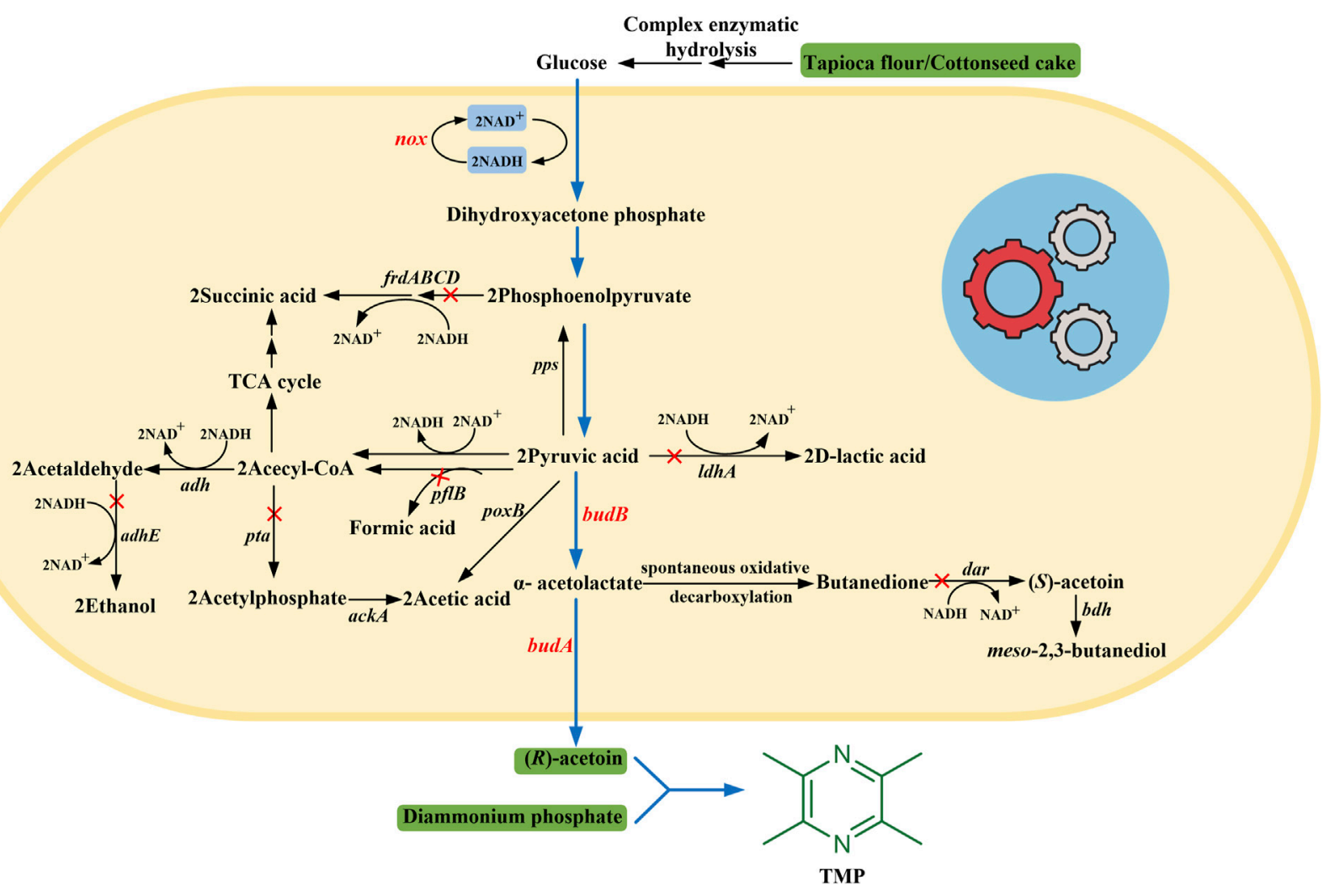

FIGURE 1 | The engineered metabolic pathway for $(R)$-AC synthesis in E. coli. The blue arrows indicate the engineered synthesis pathway of $(R)$-AC. The red cross marks indicate the disrupted pathways. budA and budB, the genes encoding a-acetolactate decarboxylase and $\alpha$-acetolactate synthase from Enterobacter cloacae, respectively; nox, the gene encoding NADH oxidase from Lactobacillus brevis; dar, diacetyl reductase gene; frdABCD, fumarate reductase gene; pfIB, pyruvate formate lyase gene; IdhA, lactate dehydrogenase gene; pta, phosphotransacetylase gene; adhE, alcohol dehydrogenase gene.

Studies regarding TMP production from various carbon and nitrogen sources using biological approaches are summarized in Table 1. Most reports employed commercial glucose as the carbon source, while costly yeast extract, peptone and tryptone were used as the major nitrogen sources. Thus, it could be deduced that most biomanufacturing, which relied heavily on refined feedstocks, was still limited by relatively high costs, therefore not suitable for an economically feasible industrial fermentation process (Zhu et al., 2010; Xiao et al., 2014). To overcome the limitation, cheaper and readily available feedstocks and efficient fermentation systems are both required to be exploited for TMP production.

In this study, we proposed a biosynthetic strategy to enable $(R)$-AC production in microbial cell factories from inexpensive non-food feedstocks and to achieve high-yield production of TMP in a high-pressure microreactor. In detail, we first constructed a whole-cell biocatalytic system for $(R)$-AC biosynthesis from glucose. To improve $(R)$-AC production, an in situ-NAD ${ }^{+}$regeneration system was introduced into recombinant strains to balance the $\mathrm{NADH} / \mathrm{NAD}^{+}$redox. Alongside this, the biosynthetic pathways of major byproducts, which are unfavorable for cell growth and the production of target products, were blocked or impaired using metabolic engineering strategies (Figure 1). Then, the hydrolysates of various non-food raw materials, which are abundantly available, were used to replace expensive carbon and nitrogen sources. The fermentation performances of different non-food feedstocks were compared. Finally, by mixing the fermentation broth with diammonium phosphate [DAP, $\left(\mathrm{NH}_{4}\right)_{2} \mathrm{HPO}_{4}$ ] in a high-pressure microreactor under suitable reaction conditions, the efficient synthesis of TMP with a high titer at $56.72 \mathrm{~g} / \mathrm{L}$ was achieved.

\section{MATERIALS AND METHODS}

\subsection{Chemicals}

TMP (98\%) was purchased from Aladdin Biochemical Technology Co., Ltd. (Shanghai, China). AC (>98\%) was obtained from Tokyo Chemical Industry Co., Ltd. (Shanghai, China). Acetonitrile (HPLC grade) was purchased from Fisher Scientific. Ampicillin was obtained from Solarbio Life Sciences (Beijing, China). Tapioca flour and cassava starch were provided by Guangxi State Farms Mingyang Biochemical Group, Inc. (Nanning, China). Potato starch and corn starch were purchased from Shanghai Kaiyang Biotechnology Co., Ltd. (Shanghai, China). Cane molasses was obtained from Guangxi Sugar Industry Group (Nanning, China). Cottonseed cake was 
TABLE 2 | Bacterial strains and plasmids used in this study.

\begin{tabular}{|c|c|c|}
\hline Strains and plasmids & Detailed information & Source \\
\hline E. coli MG1655 & Parent strain & Lab collection \\
\hline GXASR & E. coli MG1655/pTrc99A & This study \\
\hline GXASR1 & E. coli MG1655/pTrc99A-budB-budA-nox & This study \\
\hline GXASR2 & E. coli MG1655/pTrc99A-alsS-alsD-nox & This study \\
\hline GXASR3 & E. coli MG1655 $\Delta$ dar/pTrc99A-budB-budA-nox & This study \\
\hline GXASR4 & E. coli MG1655 $\triangle$ frdABCD/pTrc99A-budB-budA-nox & This study \\
\hline GXASR5 & E. coli MG1655 $\Delta$ dar $\triangle$ frdABCD/pTrc99A-budB-budA-nox & This study \\
\hline GXASR6 & E. coli MG1655 $\triangle$ dar $\triangle$ frdABCD $\triangle$ pflB/pTrc99A-budB-budA-nox & This study \\
\hline GXASR7 & E. coli MG1655 $\triangle$ dar $\triangle$ frdABCD $\triangle / d h A / p \operatorname{Trc99A-budB-budA-nox~}$ & This study \\
\hline GXASR8 & E. coli MG1655 $\Delta$ dar $\triangle$ frdABCD $\Delta$ pta/pTrc99A-budB-budA-nox & This study \\
\hline GXASR9 & E. coli MG1655 $\triangle$ dar $\triangle$ frdABCD $\triangle$ adhE/pTrc99A-budB-budA-nox & This study \\
\hline GXASR10 & E. coli MG1655 $\Delta d a r \Delta f r d A B C D \Delta p f l B \Delta / d h A / p \operatorname{Trc99A-budB-budA-nox}$ & This study \\
\hline GXASR11 & E. coli MG1655 $\Delta$ dar $\triangle$ frdABCD $\Delta p f I B \Delta / d h A \Delta p t a / p T r c 99 A-b u d B-b u d A-n o x$ & This study \\
\hline pTrc99A & $A_{m p}^{r}$ & Lab collection \\
\hline pTrc99A-budB-budA-nox & $A m p^{r}$ & This study \\
\hline pTrc99A-alsS-alsD-nox & $A m p^{r}$ & This study \\
\hline
\end{tabular}

alsD and alsS, the genes encoding $\alpha$-acetolactate decarboxylase and $\alpha$-acetolactate synthase from $P$. polymyxa, respectively.

obtained from Jinan Oumi Biotechnology Co., Ltd. (Jinan, China). Other raw nitrogen sources were purchased from Kerui Biotechnology Co., Ltd. (Qingdao, China). Thermostable a-amylase (Liquozyme Supra, $60 \mathrm{KNU} / \mathrm{ml}$ ) and glucoamylase (Dextrozyme, $350 \mathrm{AGU} / \mathrm{ml}$ ) obtained from Novozymes (Novozymes China Biotechnology Co., Ltd.) were used for liquefaction and saccharification of raw starch. The acid protease $(200 \mathrm{KU} / \mathrm{g})$ was purchased from Imperial Jade Biotechnology Co., Ltd. (Ningxia, China) for protein hydrolysis. All other chemicals used in this study were of analytical grade and commercially available. All aqueous solutions were prepared with ultrapure water $(18.2 \mathrm{M} \Omega \mathrm{cm}$, PURELAB Classic, ELGA).

\subsection{Bacterial Strains and Plasmids}

All bacterial strains and plasmids used in this study are listed in Table 2. All engineered E. coli strains were constructed from MG1655 for the biosynthesis of AC. The following genes were used in this study: $b u d A, \alpha$-acetolactate decarboxylase (GenBank accession number CP003678.1); budB, $\alpha$-acetolactate synthase (GenBank accession number CP003678.1); alsD, $\alpha$-acetolactate decarboxylase (GenBank accession number MK508992.1); alsS, $\alpha$-acetolactate synthase (GenBank accession number MK508991.1); nox, NADH oxidase (GenBank accession number AF536177.1). The codons of the above genes were optimized, and the ribosomal binding site and spacer sequence containing the nucleotide sequence taaggaggatataca were added in front of each gene and then linked into gene clusters of budBbudA-nox and alsS-alsD-nox, respectively, which were artificially synthesized by Suzhou Jinweizhi Biotechnology Co., Ltd. (Suzhou, China). To enable the production of AC and balance the cellular NADH/NAD ${ }^{+}$ratios in E. coli, expression plasmids of pTrc99A-budB-budA-nox and pTrc99A-alsS-alsD-nox were constructed and transformed into competent cells, respectively. Several mutant $E$. coli strains were constructed by stepwise deletions of genes (dar, frdABCD, pflB, ldhA, pta and adhE) encoding key enzymes in the metabolic pathways via homologous recombination to reduce by-products. The effects of metabolic pathway optimization on glucose consumption, fermentation efficiency, and finial concentrations of $\mathrm{AC}$ and by-products were investigated to screen high-yield recombinant strains.

\subsection{Culture Medium and Growth Conditions}

The Luria-Bertani (LB) medium (10.0 g/L tryptone, $5.0 \mathrm{~g} / \mathrm{L}$ yeast extract, and $10.0 \mathrm{~g} / \mathrm{L} \mathrm{NaCl})$ at $\mathrm{pH} 7.0$ was used for routine culture of $E$. coli (Xu et al., 2018). The initial fermentation medium, which contained $100.0 \mathrm{~g} / \mathrm{L}$ glucose, $10.0 \mathrm{~g} / \mathrm{L}$ peptone, $7.0 \mathrm{~g} / \mathrm{L}$ yeast extract, $\quad 0.5 \mathrm{~g} / \mathrm{L} \quad \mathrm{NaCl}, \quad 0.2 \mathrm{~g} / \mathrm{L} \quad \mathrm{MgSO}_{4}, \quad 0.5 \mathrm{~g} / \mathrm{L}$ betaine monohydrate and $0.1 \mathrm{~g} / \mathrm{L}$ thiamine, was used for $(R)-\mathrm{AC}$ production by recombinants. The $\mathrm{pH}$ was adjusted to 7.0 before sterilization. Glucose solution was sterilized separately then added into the autoclaved initial fermentation medium to make a final concentration of $100 \mathrm{~g} / \mathrm{L}$ before inoculation. Ampicillin was added into the medium as required with a final concentration of $0.1 \mathrm{~g} / \mathrm{L}$. Five percent $(\mathrm{v} / \mathrm{v})$ of the inoculant was used for all fermentation processes unless indicated otherwise. All strains were incubated in $250 \mathrm{ml}$ Erlenmeyer flasks with maximally $50 \mathrm{ml}$ medium at $37^{\circ} \mathrm{C}$ on a rotary shaker at $250 \mathrm{rpm}$. Cell growth was determined via $\mathrm{OD}_{600}$ (optical density at $600 \mathrm{~nm}$ ) using a DU 800 spectrophotometer (Beckman Coulter). All the experiments in shake flasks were performed in triplicate.

\subsection{Preparation of Non-Food Medium}

Instead of commercial carbon and nitrogen sources, the non-food medium containing fermentable sugar and nitrogen derived from raw materials by enzymatic hydrolysis was prepared in three consecutive steps: pre-treatment, liquefaction, and saccharification-protein hydrolysis. In the pre-treatment step, $56.4 \mathrm{~g}$ tapioca flour and $20.1 \mathrm{~g}$ cottonseed cake were added into a $500 \mathrm{ml}$ Erlenmeyer flask with $300 \mathrm{ml}$ tap water. The $\mathrm{pH}$ was adjusted to 6.3 using $20 \% \mathrm{NaOH}$ solution and $7.5 \mathrm{ml}$ $\alpha$-amylase solution $\left(0.5 \mathrm{~g} \mathrm{CaCl}_{2}\right.$ was added to $2 \mathrm{ml} \alpha$-amylase, then the final volume was adjusted to $100 \mathrm{ml}$ with distilled water) 
was added before autoclaving at $121^{\circ} \mathrm{C}$ for $15 \mathrm{~min}$ to degrade the structure of starch grains for better hydrolysis performance. In the subsequent liquefaction step, the $\mathrm{pH}$ was adjusted to 6.3 and $15 \mathrm{ml} \alpha$-amylase solution was added. The hydrolysate was incubated on a water bath shaker $\left(95^{\circ} \mathrm{C}, 160 \mathrm{rpm}\right)$ for $1 \mathrm{~h}$ and allowed to cool. In the last step, the hydrolysate was adjusted to $\mathrm{pH} 4.3$ using $20 \% \mathrm{H}_{2} \mathrm{SO}_{4}$ solution and then treated with $22.5 \mathrm{ml}$ glucoamylase solution ( $4 \mathrm{ml}$ glucoamylase was diluted to $100 \mathrm{ml}$ with distilled water) and $0.6 \mathrm{~g}$ acid protease on a water bath shaker $\left(55^{\circ} \mathrm{C}, 160 \mathrm{rpm}\right)$ for $20 \mathrm{~h}$. Afterwards, the $\mathrm{pH}$ was readjusted to 7.0 using $20 \% \mathrm{NaOH}$ solution and the supernatant was collected by centrifugation at $6,000 \mathrm{rpm}$ for $5 \mathrm{~min}$. The final non-food medium was sterilized at $115^{\circ} \mathrm{C}$ for $15 \mathrm{~min}$.

\subsection{Optimization of Fermentation Parameters for AC Synthesis}

The optimal fermentation conditions were identified respectively in shake flasks and 1-L fermenters according to the titer of $(R)$ AC. In shake-flask fermentation, four fermentation parameters (temperature, fermentation volume, inoculation proportion and rotate speed) were investigated. Fermentation conditions, including the initial $\mathrm{pH}$, aeration rate and agitation speed, were optimized in a multiple parallel fermenter system (1-L working volume, BLBIO-1GC-5-H, Shanghai Bailun BioTechnology Co., Ltd.) with an initial broth volume of $0.5 \mathrm{~L}$. During the entire fermentation, the concentrations of residual glucose and $(R)$-AC were examined regularly. The fermentation process was terminated when the residual glucose decreased below $5 \mathrm{~g} / \mathrm{L}$.

\subsection{Fed-Batch Fermentation}

Based on the optimal condition determined from preliminary work, a 5-L fermenter (BIOTECH-5BG, Shanghai Baoxing BioEngineering Equipment Co., Ltd.) was employed to achieve higher $(R)$-AC production via fed-batch fermentation. When the residual glucose in the fermentation broth fell below $40 \mathrm{~g} /$ $\mathrm{L}$, the concentrated hydrolysates of tapioca flour and cottonseed cake by rotary evaporation were supplemented to make the glucose to approximately $140 \mathrm{~g} / \mathrm{L}$. The fermentation process was terminated when the residual glucose declined to $10 \mathrm{~g} / \mathrm{L}$ or when the titer of (R)-AC stopped increasing. The concentrations of $(R)-\mathrm{AC}$ and major by-products were analyzed using gas chromatography (GC) and highperformance liquid chromatography (HPLC), respectively.

\subsection{Synthesis of}

\section{2,3,5,6-Tetramethylpyrazine}

An appropriate ammonium salt is crucial to the synthesis of TMP. Previous studies have revealed that DAP was the most efficient ammonium salt to support TMP synthesis among various ammonium sources (Zhu and Xu 2010b; Zhong et al., 2020a). The reaction system in this study was a mixture of fermentation broth and DAP at a total volume of $20 \mathrm{ml}$. All condensation reactions were carried out in a high-pressure microreactor (LHK-25, OLEBVAP Instrument and Equipment Co., Ltd., China). To improve the efficiency of TMP production, reaction parameters including temperature, rotation speed, reaction time, the molar ratio of $\mathrm{AC} / \mathrm{DAP}$ and the initial $\mathrm{pH}$ were optimized. Due to the poor water solubility of TMP, ethanol was added into the reaction mixture to reach a volume content of $60 \%$ after the condensation reaction (Xu et al., 2018). After ultrasonication for $5 \mathrm{~min}$, the reaction solution was centrifuged at $12,000 \mathrm{rpm}$ for $2 \mathrm{~min}$ to resolve the TMP into ethanol. The solution was filtered, then immediately subjected to GC analysis after an appropriate dilution.

\subsection{Analytical Methods}

The fermentation broth was centrifuged at 12,000 rpm for $2 \mathrm{~min}$, then the supernatant was collected and diluted for the determination of residual glucose concentration using a biosensor analyzer (SBA-40D, Shandong, China). The nitrogen content in the raw materials was calculated according to the production instructions.

The concentrations of AC and TMP were determined by a GCFID system (Agilent 7890A) equipped with a polar column (Phenomenex ZB-WAX Plus, $30 \mathrm{~m} \times 0.32 \mathrm{~mm} \times 0.25 \mu \mathrm{m}$ ) with nitrogen as carrier gas at a constant flow of $1.6 \mathrm{ml} / \mathrm{min}$. The column oven temperature was maintained at $100^{\circ} \mathrm{C}$ for $1 \mathrm{~min}, 20^{\circ} \mathrm{C} / \mathrm{min}$ ramp until $180^{\circ} \mathrm{C}$, and held at $180^{\circ} \mathrm{C}$ for $3 \mathrm{~min}$. The injector and detector temperatures were both at $250^{\circ} \mathrm{C}$. The concentrations of AC and TMP were calculated by the internal standard method using acetonitrile as an internal standard.

The concentrations of $(R)$-AC and $(S)$-AC in the fermentation broth were analyzed as described in our previous study (Li et al., 2018). Briefly, (R)-AC and (S)-AC in the supernatant of fermentation broth were extracted with ethyl acetate and differentiated by the GC system (Agilent 7890A) equipped with a chiral column (Agilent CycloSil-B, $0.32 \mathrm{~mm} \times$ $0.25 \mathrm{~mm} \times 30 \mathrm{~m})$. The optical purity of $(R)$-AC was calculated as follows: $(R) /[(S)+(R)] \times 100 \%$, where $(R)$ and $(S)$ represented the concentrations of $(R)$-AC and $(S)$-AC, respectively.

The fermentation broth was centrifuged at $13,000 \mathrm{rpm}$ for $5 \mathrm{~min}$ and the supernatant was filtered through a $0.2-\mu \mathrm{m}$ nylon syringe filter. The main by-products, including acetate, succinate, formate and lactate, were determined using HPLC equipped with a Carbomix H-NP5 column $(8 \%, 7.8 \times 300 \mathrm{~mm}$, Sepax Technologies) at $55^{\circ} \mathrm{C}$. The analysis was conducted with a mobile phase of $2.5 \mathrm{mM} \mathrm{H}_{2} \mathrm{SO}_{4}$ at a flow rate of $0.6 \mathrm{ml} / \mathrm{min}$ and the UV detection wavelength was $210 \mathrm{~nm}$. The injection volume of each sample was $10 \mu \mathrm{L}$. The by-product 2,3-butanediol (2,3-BD) was determined by a GC-FID system as mentioned above.

\section{RESULTS AND DISCUSSION}

\subsection{Screening of Suitable Genes Derived From Different Microbial Sources for AC Production}

The synthesis of TMP by microorganisms, including Bacillus sp., (Xiao et al., 2006), Corynebacterium sp. (Dickschat et al., 2010), 
Lactococcus sp. (Kim et al., 1994), Chondromyces sp. (Dickschat et al., 2005), Streptomyces sp. (Braña et al., 2014) and Monacus sp. (Jia et al., 2017a), has been previously reported. However, the maximum production of TMP from the above microorganisms was only $4.33 \mathrm{~g} / \mathrm{L}$, which significantly hindered the industrial application. Regarding the synthesis mechanism of TMP in vivo, there exist two conflicting viewpoints. Compared with a standpoint of an enzymatic condensation process, the predominant experimental results tend to support the viewpoint that the precursor of TMP was biosynthesized in vivo whereas the subsequent condensation was an in vitro nonenzymatic process (Zhu et al., 2010; Xiao et al., 2014). Hence, it was essential to investigate the biosynthesis process of AC, which was the limiting step for TMP synthesis, and further tackle the problem of low AC production.

Biosynthesis of AC by endogenous strains has been widely reported (Romano and Suzzi, 1996; Cui et al., 2020; Lu et al., 2020; Zhong et al., 2020b). Nevertheless, wild-type strains often suffered from low capability in AC generation (Xiao et al., 2010; Xu et al., 2015; Guo et al., 2017). Fortunately, the synthesis of AC directed by genes from different bacteria species could be achieved in heterologous hosts by genetic engineering approaches (Yamada-Onodera et al., 2002), therefore the selection of suitable non-native producers is of great importance. Amongst engineered microbial strains for AC biosynthesis, E. coli is frequently used as a desirable candidate due to a comprehensive understanding of the metabolisms and wellestablished genetic engineering tools (Adamczyk and Reed 2017). The $\alpha$-acetolactate synthase and $\alpha$-acetolactate decarboxylase are two crucial enzymes involved in AC biosynthetic pathway (Celińska and Grajek 2009; Ji et al., 2011; Jang et al., 2017). Because of the compatibility with the chassis cells, the selection of suitable genes from proper donors is one of the key issues (Xiao and Lu 2014). Additionally, as shown in Figure 1, excess NADH would be generated during the production of $(R)$-AC by $E$. coli. To balance the in vivo NADH/NAD ${ }^{+}$redox, the bypasses of organic acids and alcohols must be activated to consume the surplus NADH. By the expression of exogenous NADH oxidase, the synthesis of by-products could be diminished, consequently leading to the redistribution of carbon flux for $(R)$-AC (Sun et al., 2012; Zhang et al., 2014).

Here, we compared the AC production efficiencies of two recombinants, which carried different genes encoding $\alpha$-acetolactate decarboxylase and $\alpha$-acetolactate synthase from E. cloacae and P. polymyxa, respectively. Meanwhile, the gene of $\mathrm{NADH}$ oxidase from $L$. brevis was introduced into the recombinants to construct an endogenous cofactor regeneration system. Figure $\mathbf{2 C}$ showed that the strain GXASR (pTrc99A) was incapable of producing $(R)$-AC during fermentation. In contrast, the $(R)$-AC production of strain GXASR1 (pTrc99A-budB-budA-nox) achieved $30.59 \mathrm{~g} / \mathrm{L}$, which represented a 1.87-fold increase compared to strain GXASR2 (pTrc99A-alsS-alsD-nox) (16.37 g/L). These results demonstrated that the exogenous genes derived from both $E$. cloacae and P. polymyxa were effectively expressed in E. coli, enabling efficient $(R)$-AC production. Moreover, the accumulation of $(R)-\mathrm{AC}$, cell growth and glucose-consuming ability of strain GXASR1 were all far surpassing that of strain GXASR2. This was because the activities of enzymes from different gene sources could vary widely (Nadal et al., 2009; Xu et al., 2015). In our case, genes of $b u d B$ and $b u d A$ from $E$. cloacae could probably express $\alpha$-acetolactate synthase and $\alpha$-acetolactate decarboxylase with higher activities. A similar result was observed by $\mathrm{Xu}$ et al. (2018) when comparing the AC production from recombinants carrying different exogenous genes, and they speculated that it was because Enterobacter had a close codon preference with $E$. coli and both of them belonged to the Enterobacteriaceae.

\subsection{Effect of Inducer Concentrations}

As the improvement of the enzymatic activities and protein expression efficiency could enhance the AC production, we further examined the effect of inducer concentrations on $(R)$ AC production for strain GXASR1. It was essential to optimize the concentration of isopropyl- $\beta$-D-thiogalactopyranoside (IPTG) because protein expression was not positively related to IPTG concentration (Couto et al., 2017). When $\mathrm{OD}_{600}$ reached approximately 2.0, different concentrations $(0-1.00 \mathrm{mM})$ of IPTG were evaluated for induction. As shown in Table 3, the production of $(R)-\mathrm{AC}$ attained $30.59 \mathrm{~g} / \mathrm{L}$ without induction, whereas a higher titer of $(R)-A C$ at $32.70 \mathrm{~g} / \mathrm{L}$ was detected in the presence of $0.01 \mathrm{mM}$ IPTG. The pTrc99A plasmid is a constitutive expression vector, while the trc promoter is also inducible by IPTG, which is an analogue of lactose binding specifically to the repressor protein of the lac operon. The addition of IPTG into the medium could make up for the insufficiency of lac inducer expressed by the pTrc99A plasmid, resulting in higher expression of plasmid and therefore enhanced the production of $(R)$-AC. However, both the cell growth and the $(R)$-AC synthesis ability of strain GXASR1 gradually decreased along with the increase of IPTG concentration. Considering that IPTG was not an innocuous inducer, this result indicated that there was a toxic effect of excessive IPTG on the cell proliferation as well as $(R)$-AC productivity of GXASR1. Therefore, a final concentration of IPTG at $0.01 \mathrm{mM}$ was the most desirable for recombinant cell induction and was adopted in the following experiments.

\subsection{Optimization of Metabolic Pathways in Recombinant Strains}

As illustrated in Figure 1, a variety of by-products were produced along with the biosynthesis of $(R)$-AC, which led to a decrease of carbon flux in the synthetic pathway of $(R)$-AC and therefore restricted its production. Our results showed that $(R)-\mathrm{AC}$ produced by GXASR1 reached a titer of $32.70 \mathrm{~g} / \mathrm{L}$ with an optical purity of $99.14 \%$, while the main by-products were determined as $3.37 \mathrm{~g} / \mathrm{L}$ 2,3-BD, $2.13 \mathrm{~g} / \mathrm{L}$ acetate, $0.63 \mathrm{~g} / \mathrm{L}$ lactate, $0.41 \mathrm{~g} / \mathrm{L}$ formate, $0.37 \mathrm{~g} / \mathrm{L}$ ethanol and $1.44 \mathrm{~g} / \mathrm{L}$ succinate. Genetic manipulation on critical metabolic nodes has been widely used to reconstruct the metabolic network of microbial cells. It has been reported that different genes encoding pathway enzymes, which catalyzed the formation of diverse byproducts, were deleted from the microbial genome to facilitate the 

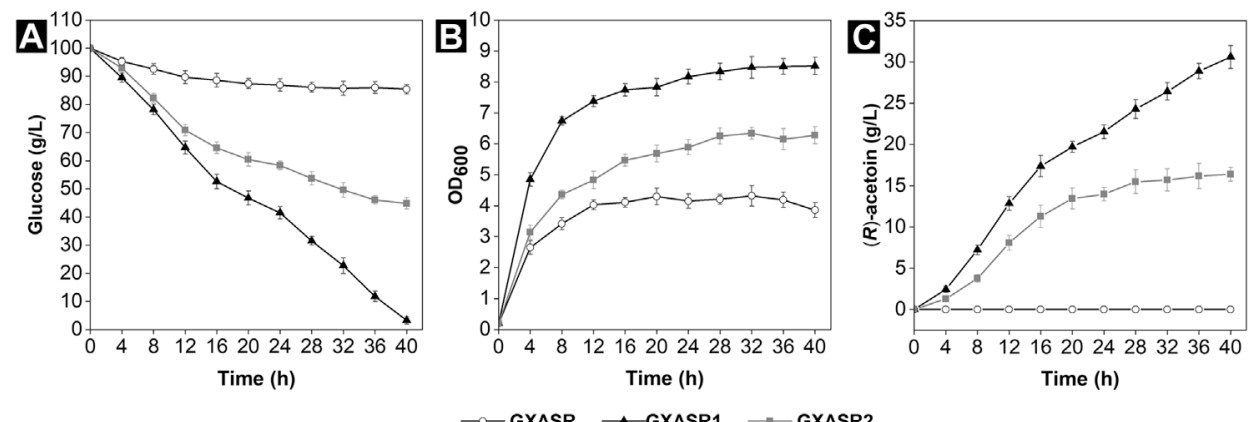

FIGURE 2 | Synthesis of (R)-AC by GXASR (pTrc99A) and genetically engineered strains harboring different exogenous genes using 50 ml initial fermentation medium at $\mathrm{pH} 7.0 \mathrm{in} 250 \mathrm{ml}$ shake flasks at $250 \mathrm{rpm}$ and $37^{\circ} \mathrm{C}$ for $40 \mathrm{~h}$ (A) residual glucose (B) cell growth (C) $(R)$-AC production. Error bars represent the standard deviations.

TABLE 3 | Fermentation performances (mean \pm SD) of $E$. coli GXASR1 under different IPTG induced concentrations in $40 \mathrm{~h}$.

\begin{tabular}{|c|c|c|c|c|c|c|}
\hline Strain & IPTG (mM) & Glucose consumed (g/L) & $O_{600}$ & $(R)-A C(g / L)$ & Yield $(g / g)^{a}$ & Productivity $\left[g /(L \cdot h)^{b}\right]$ \\
\hline \multirow[t]{5}{*}{ GXASR1 } & 0 & $96.8 \pm 0.6$ & $8.52 \pm 0.18$ & $30.59 \pm 1.15$ & 0.32 & 0.76 \\
\hline & 0.01 & $97.3 \pm 1.3$ & $8.48 \pm 0.37$ & $32.70 \pm 0.68$ & 0.34 & 0.82 \\
\hline & 0.05 & $95.1 \pm 2.1$ & $8.26 \pm 0.49$ & $28.64 \pm 0.93$ & 0.30 & 0.72 \\
\hline & 0.10 & $93.6 \pm 1.6$ & $7.96 \pm 0.51$ & $27.38 \pm 0.55$ & 0.29 & 0.68 \\
\hline & 1.00 & $86.7 \pm 2.3$ & $6.8 \pm 0.35$ & $22.44 \pm 0.63$ & 0.26 & 0.56 \\
\hline
\end{tabular}

${ }^{a}$ Production of $\mathrm{AC} / \mathrm{glucose}$ consumption.

${ }^{b}$ Production of AC/fermentation time; $S D$, standard deviation, $n=3$.

AC production (Förster et al., 2017; Jang et al., 2017). Consequently, after analyzing the metabolic pathway of the host bacteria we performed genetic modification to block the biosynthetic pathways of major by-products which were not essential for cell growth. In detail, we first deleted the diacetyl reductase gene (dar) to decrease the flux from $\alpha$-acetolactate to meso-2,3-BD via $(S)$-AC (Figure 1). After dar gene deletion, 2,3BD was still produced by GXASR3, but its concentration markedly dropped by $57.27 \%$ while the production of $(R)$-AC slightly increased from 32.70 to $34.65 \mathrm{~g} / \mathrm{L}$ (Table 4). Parallelly, we deleted the fumarate reductase gene $(f r d A B C D)$ to impair the synthesis of succinate, resulting in an $11.44 \%$ increase of $(R)$ AC in GXASR4 $(\triangle f r d A B C D)$ compared to that in GXASR1. The concentrations of 2,3-BD and succinate from the double knockout GXASR5 ( $\triangle$ dar $\triangle$ frdABCD) dramatically decreased 63.20 and $83.33 \%$ compared to that from GXASR1, respectively. Compared with GXASR1, the strain of GXASR5 ( $\triangle$ dar $\triangle$ frdABCD) showed a $63.20 \%$ decrease in 2,3-BD and an $83.33 \%$ decrease in succinate. Besides, the output of $(R)$-AC improved about $13.94 \%$ with a higher enantiomeric purity.

Based on the double knockout strain GXASR5, the genes of $p f l B, l d h A, p t a$ and $a d h E$ were respectively deleted to construct triple knockouts of GXASR6 ( $\triangle$ dar $\triangle$ frdABCD $\triangle p f l B)$, GXASR7 ( $\triangle$ dar $\triangle$ frdABCD $\triangle l d h A$ ), GXASR8 ( $\triangle$ dar $\triangle$ frdABCD $\triangle p t a)$ and GXASR9 ( $\triangle$ dar $\triangle$ frdABCD $\triangle a d h E$ ). The synthesis pathway of formate was successfully blocked in GXASR6 ( $\triangle$ dar $\triangle$ frdABCD $\triangle p f l B)$ since no formate was detected during fermentation. The production of lactate declined from $0.69 \mathrm{~g} / \mathrm{L}$ in GXASR5 to $0.24 \mathrm{~g} / \mathrm{L}$ in GXASR7, while the concentration of acetate in GXASR8 was reduced by $73.24 \%$. Additionally, the productions of $(R)-\mathrm{AC}$ in GXASR6, GXASR7 and GXASR8 were slightly higher than that of GXASR5. The results demonstrated that further deletion of $p f l B, l d h A$ and $p t a$ positively affected the accumulation of AC.

The mutant GXASR9 devoid of $a d h E$ was unable to produce ethanol. However, as the glucose consumption was significantly reduced, the AC output declined to $19.74 \mathrm{~g} / \mathrm{L}$, approximately $50 \%$ of that in GXASR5. This observation was in agreement with other studies (Li et al., 2015a; Förster et al., 2017), indicating that deletion of adhE negatively affected the cell growth and metabolism, and eventually led to a significant decrease of AC. Therefore, instead of deleting $a d h E$, the quadruple and quintuple knockouts of GXASR10 ( $\triangle$ dar $\triangle$ frdABCD $\triangle p f l B \Delta l d h A)$ and GXASR11 ( $\triangle$ dar $\triangle f r d A B C D \triangle p f l B \Delta l d h A \Delta p t a$ ) were further constructed respectively. Among all the recombinants, GXASR11 yielded the highest level of $(R)-\mathrm{AC}$ at $40.84 \mathrm{~g} / \mathrm{L}$ with an enantiomeric purity of $99.42 \%$ (Table 4), which was higher than that obtained (97.3\%) by Xu et al. (2015) using metabolic engineered $E$. coli involving the budAB genes for $(R)-\mathrm{AC}$ biosynthesis. Although a small amount of ethanol was accumulated by this deletion mutant, the concentrations of other by-products obviously descended while no formate was produced, indicating that the deletions of dar, frdABCD, pflB, $l d h A$ and $p t a$ were beneficial for the synthesis of $(R)$-AC. As a result, GXASR11 was chosen as the best AC producer for the 


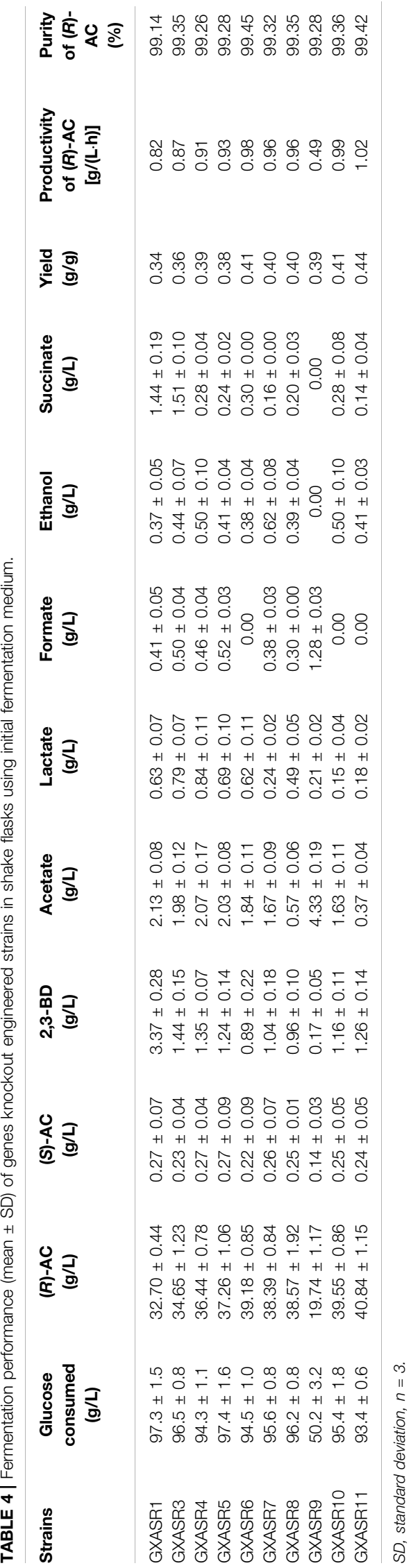

subsequent fermentation experiments in shake flasks and fermenters.

\subsection{Screening for Optimal Carbon Source and Concentration}

To provide an eco-friendly and economical bio-based alternative for AC and TMP production, not only the yield and productivity of the biosynthetic process should be optimized for precursor production, but also the cost of manufacture, particularly fermentation medium costs, needs to be carefully evaluated. Glucose is a common carbon source used in laboratory-scale cultivation processes for heterotrophic microorganisms. As the cost of raw materials significantly contributes to the manufacturing cost of target products, refined glucose is not desirable for practical production due to its relatively high price. Therefore, in place of using glucose as the sole carbon source, here we employed several cheap and abundant feedstocks for $(R)$-AC biosynthesis aiming to reduce the overall manufacturing cost of TMP.

The fermentation performances of glucose and five different non-food carbon sources (cane molasses, corn starch, potato starch, cassava starch and tapioca flour) for $(R)$-AC production by engineered $E$. coli were compared. Different raw materials were converted into fermentable sugar (i.e., glucose) by enzymatic hydrolysis, which was added into the non-food medium to obtain an initial glucose concentration of $100 \mathrm{~g} / \mathrm{L}$. Fermentation was carried out in shake flasks for $40 \mathrm{~h}$, by the end of which the production of $(R)$-AC and the concentration of residual glucose were examined. As shown in Figure 3A, the hydrolyzed cane molasses gave the lowest $(R)$-AC production $(15.81 \mathrm{~g} / \mathrm{L})$ among all carbon sources, while the residual glucose concentration was up to $17.4 \mathrm{~g} / \mathrm{L}$. Though cane molasses could be directly utilized in fermentation by yeasts for a high yield of ethanol and other chemicals (Basso et al., 2011; Abubaker et al., 2012), it could not be effectively metabolized by GXASR11. This is because the major component of cane molasses is sucrose, a kind of nonreducing sugar (Su et al., 2021), and the ability and efficiency of $E$. coli to consume sucrose depend on the specific strain used (Reid and Abratt 2005; Mohamed et al., 2019). The hydrolyzed corn starch and potato starch could provide glucose for fermentation (Liu 2002; Chen and Zhang 2012), however, the high viscosity of these hydrolysates led to low efficiency in mass transfer, resulting in a negative impact on cell growth and $(R)$-AC production. The outputs of $(R)$-AC from hydrolyzed cassava starch and tapioca flour reached $42.24 \mathrm{~g} / \mathrm{L}$ and $43.55 \mathrm{~g} / \mathrm{L}$, respectively, both of which surpassed that from glucose $(40.84 \mathrm{~g} / \mathrm{L})$. These hydrolysates were relatively less viscous than that of corn starch and potato starch, thus they did not negatively affect the mass transfer. Moreover, besides the glucose hydrolyzed from starch, amino acids and fatty acids were also released from the plant-derived constituents, serving as nutrients and growth factors for cell proliferation and resulting in more efficient $(R)$-AC synthesis. Additionally, the processing technology of tapioca flour, which only involved processes of dehydration and grinding for the peeled cassava root, was much easier and less costly than that of cassava starch, which required an extra refining process. Given that the price of tapioca flour was approximately 30-50\% lower than that of 

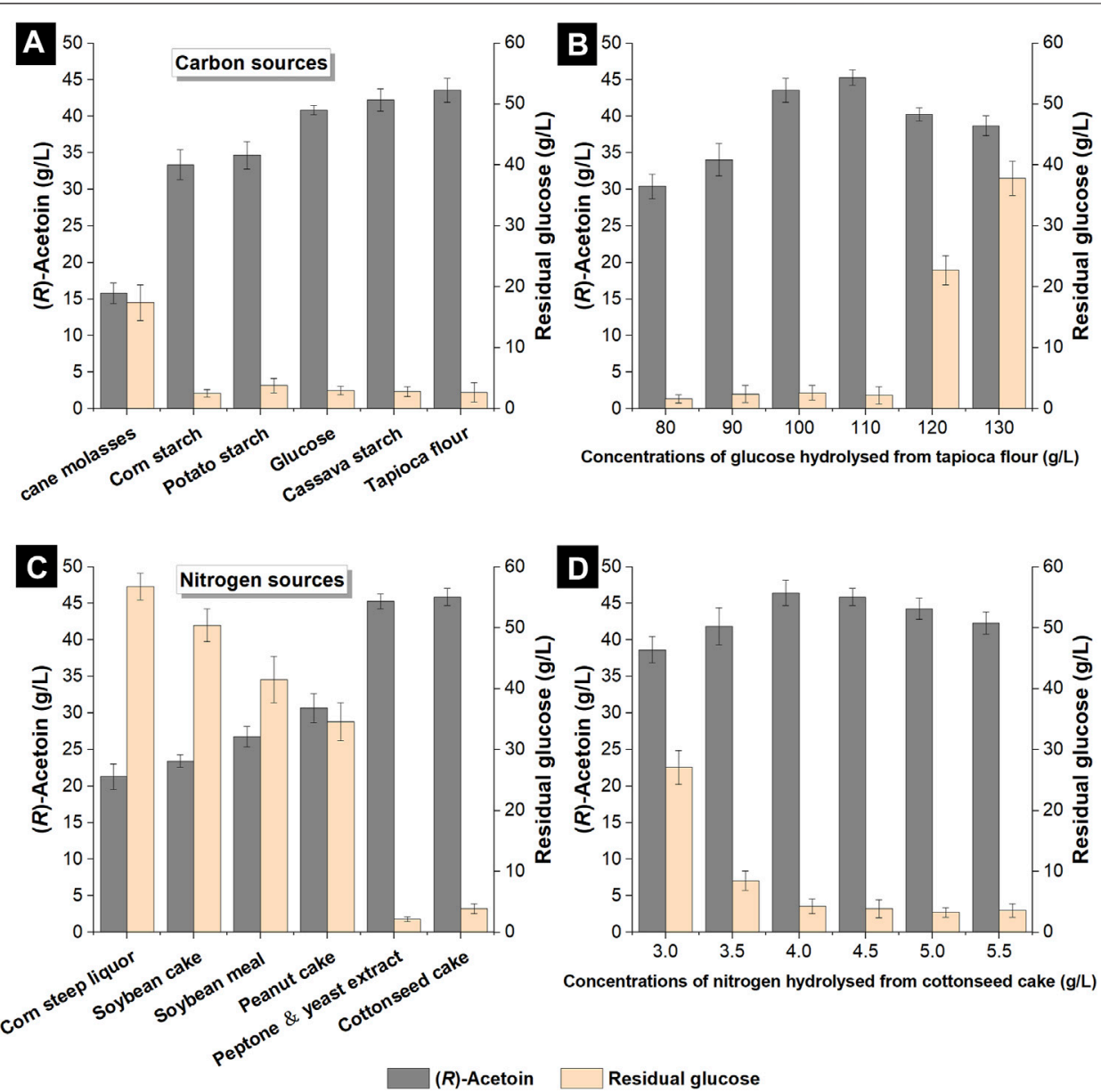

FIGURE 3 | Effects of different carbon and nitrogen sources from hydrolysates of cheap raw materials on the production of ( $R$ )-AC by GXASR11 in 250 ml shake flasks at $250 \mathrm{rpm}$ and $37^{\circ} \mathrm{C}$. (A) various carbon sources (B) effects of glucose concentrations on (R)-AC production (C) various nitrogen sources (D) effects of nitrogen concentrations on $(R)-\mathrm{AC}$ production.

cassava starch as well as its accessibility, tapioca flour was selected as the optimal alternative carbon source for $(R)$-AC fermentation.

To assess the optimal concentration of tapioca flour, its hydrolysate was prepared to obtain $80-130 \mathrm{~g} / \mathrm{L}$ glucose in the non-food medium. The production of $(R)$-AC by GXASR11 was examined when the residual glucose fell below $5 \mathrm{~g} / \mathrm{L}$ or remained unchanged in the fermentation broth. As shown in Figure 3B, the concentration of $(R)$-AC increased along with the increase of glucose concentration from 80 to $110 \mathrm{~g} / \mathrm{L}$, and peaked at $110 \mathrm{~g} / \mathrm{L}$ glucose with an $\mathrm{AC}$ output of $45.28 \mathrm{~g} / \mathrm{L}$. Nevertheless, as the glucose level rose to 120 or $130 \mathrm{~g} / \mathrm{L}$, the glucose consumption of engineered strain significantly dropped, as well as the output of AC. This was probably due to the increase of osmotic pressure and viscosity of the fermentation broth, which in turn inhibited the cell growth (data not shown) and mass transfer efficiency.

\subsection{Screening for Optimal Nitrogen Source and Concentration}

The final composition of the non-food medium was determined by a combination of the optimum carbon and nitrogen sources, hence we further compared five different raw materials with the refined nitrogen source as shown in Figure 3C. Although nitrogen sources were not served as substrates for $(R)$-AC synthesis, nitrogen was an essential component of cell structure and enzymes, which therefore strongly influenced the fermentation efficiency of $(R)$-AC. The non-food medium was prepared by adding hydrolysates of raw materials to obtain $4.5 \mathrm{~g} / \mathrm{L}$ total nitrogen.

Figure 3C showed that the hydrolysates of corn steep liquor, soybean cake, soybean meal and peanut cake were not beneficial nitrogen sources for $(R)$-AC production by GXASR11, because by the end of fermentation, the concentration of residual glucose was in the range between $34.6 \mathrm{~g} / \mathrm{L}$ and $56.8 \mathrm{~g} / \mathrm{L}$, and the output of $(R)-\mathrm{AC}$ was between $21.28 \mathrm{~g} / \mathrm{L}$ and $30.66 \mathrm{~g} / \mathrm{L}$. In contrast, the peptone and yeast extract were good nitrogen sources for $(R)$-AC biosynthesis because the titer achieved $45.28 \mathrm{~g} / \mathrm{L}$ at $40 \mathrm{~h}$. The hydrolyzed cottonseed cake turned out to be an equally promising nitrogen source for GXASR11 because a slightly higher output of $(R)$-AC at $45.89 \mathrm{~g} / \mathrm{L}$ was achieved. As commonly used nitrogen sources for microbial cultivation, peptone and yeast extract could be directly utilized by microbial cells, whereas other cheap feedstocks should be enzymatically hydrolyzed into amino acids or smaller compounds 
before being metabolized by the recombinant E. coli. However, due to the economic factor (according to the price from Sigma Aldrich, yeast extract and peptone for microbiology were about \$198 and $\$ 350$ per kg, respectively), their usage was hampered in industrialscale production. The differences in $(R)$-AC production of various feedstocks probably resulted from different hydrolysis efficiency by acid protease for the same weight of raw materials. We speculated that cottonseed cake was possibly hydrolyzed more sufficiently. In addition, the cottonseed cake contained small amounts of sugars and esters, which might contribute to the higher production of $(R)-\mathrm{AC}$ as well. These results proved the advantages that made cottonseed cake an excellent substitute for peptone and yeast extract for $(R)-\mathrm{AC}$ production. The concentration of nitrogen hydrolyzed from cottonseed cake was also optimized. As seen in Figure 3D, $4.0 \mathrm{~g} /$ $\mathrm{L}$ nitrogen from hydrolyzed cottonseed cake resulted in a maximal (R)-AC output at $46.46 \mathrm{~g} / \mathrm{L}$.

\subsection{Optimization of Raw Material Hydrolysis Process for (R)-AC Production}

The hydrolysis process of raw materials is of great significance to better utilization of low-value feedstocks for efficient AC production (Xiao et al., 2007; Zhong et al., 2020b). To acquire the optimum hydrolysis procedure, the effects of enzyme dose and hydrolysis time were investigated by single-factor experiments. As observed from Table 5, the tapioca flour was hydrolyzed by different dosages of $\alpha$-amylase and glucoamylase for different time $(8,12,16,20$ and $24 \mathrm{~h})$. The $\alpha$-amylase could hydrolyze the $\alpha-1,4$ linkages in tapioca flour to produce dextrin, oligosaccharides and monosaccharides (Lévêque et al., 2000). This enzymatic processing of starch allowed a rapid reduction in the viscosity of the hydrolysate. The partially hydrolyzed starch by $\alpha$-amylase was further treated with glucoamylase, which further hydrolyzed the chemical bonds of $\alpha-1,4$ and $\alpha-1,6$ to produce glucose (Ruiz et al., 2011). On the other hand, the cottonseed cake was hydrolyzed by the acid protease to generate amino acids before being utilized by E. coli as nitrogen sources. It was subjected to the acid protease at different enzyme/substrate ratios of 1, 2, 3, 4 and $5 \mathrm{KU} / \mathrm{g}$, respectively. Given the factors including the efficiency of hydrolysis, economic feasibility and processing period, the optimum hydrolysis condition was set as follows: $\alpha$-amylase $0.5 \mathrm{KNU} / \mathrm{g}$, glucoamylase $5 \mathrm{AGU} / \mathrm{g}$, acid protease $3 \mathrm{KU} / \mathrm{g}$ and $20 \mathrm{~h}$ for hydrolysis.

\subsection{Optimization of Fermentation Condition in Shake Flasks}

After optimizing the constituents for the non-food medium, we further evaluated the effects of temperature, fermentation volume, inoculation proportion and rotation speed for $(R)$ AC fermentation in shake flasks. Generally, the optimal growth temperature for $E$. coli was about $37^{\circ} \mathrm{C}$, but lower or higher temperatures were often employed during the synthesis of certain metabolites. For instance, a titer of $(R)$ $\mathrm{AC}$ at $38.3 \mathrm{~g} / \mathrm{L}$ was achieved by engineered $E$. coli at $35^{\circ} \mathrm{C}$ in $45 \mathrm{ml}$ fermentation medium (Xu et al., 2015). Even lower temperature $\left(30^{\circ} \mathrm{C}\right)$ was employed for $\mathrm{AC}$ production with
TABLE 5 | Effects of enzymatic hydrolysis conditions on the production of $(R)$-AC (mean \pm SD) in shake flasks.

\begin{tabular}{|c|c|c|}
\hline $\begin{array}{l}\text { Enzymatic } \\
\text { hydrolysis conditions }\end{array}$ & $(R)-A C(g / L)$ & Residual glucose (g/L) \\
\hline \multicolumn{3}{|l|}{ Alpha-amylase (KNU/g) } \\
\hline 0.1 & $28.44 \pm 0.83$ & $38.8 \pm 2.2$ \\
\hline 0.3 & $37.63 \pm 1.57$ & $29.2 \pm 1.8$ \\
\hline 0.5 & $46.59 \pm 2.04$ & $3.8 \pm 1.6$ \\
\hline 0.7 & $46.46 \pm 1.78$ & $4.3 \pm 1.2$ \\
\hline 0.9 & $46.72 \pm 1.44$ & $3.5 \pm 1.8$ \\
\hline \multicolumn{3}{|l|}{ Glucoamylase (AGU/g) } \\
\hline 1 & $35.66 \pm 1.81$ & $26.6 \pm 2.6$ \\
\hline 3 & $41.25 \pm 1.65$ & $20.1 \pm 1.2$ \\
\hline 5 & $46.70 \pm 1.93$ & $4.6 \pm 0.9$ \\
\hline 7 & $46.59 \pm 2.04$ & $3.8 \pm 1.6$ \\
\hline 9 & $46.68 \pm 1.26$ & $4.3 \pm 1.5$ \\
\hline \multicolumn{3}{|l|}{ Acid protease (KU/g) } \\
\hline 1 & $37.36 \pm 1.04$ & $16.9 \pm 1.5$ \\
\hline 2 & $46.70 \pm 1.93$ & $4.6 \pm 0.9$ \\
\hline 3 & $48.27 \pm 2.11$ & $3.7 \pm 1.2$ \\
\hline 4 & $48.32 \pm 1.85$ & $2.9 \pm 0.9$ \\
\hline 5 & $48.22 \pm 1.69$ & $3.4 \pm 1.1$ \\
\hline \multicolumn{3}{|l|}{ Saccharification time (h) } \\
\hline 8 & $30.53 \pm 1.26$ & $43.6 \pm 2.3$ \\
\hline 12 & $39.64 \pm 0.86$ & $25.7 \pm 1.6$ \\
\hline 16 & $44.26 \pm 1.62$ & $14.6 \pm 0.9$ \\
\hline 20 & $48.27 \pm 2.11$ & $3.7 \pm 1.2$ \\
\hline 24 & $48.35 \pm 1.88$ & $2.8 \pm 0.6$ \\
\hline
\end{tabular}

$S D$, standard deviation, $n=3$.

mutant E. coli in anaerobic fermentation (Förster et al., 2017). Hence, we investigated the $(R)$-AC production by GXASR 11 at $33^{\circ} \mathrm{C}, 35^{\circ} \mathrm{C}, 37^{\circ} \mathrm{C}, 39^{\circ} \mathrm{C}$ and $41^{\circ} \mathrm{C}$, respectively. As seen in Figure $4 \mathrm{~A}$, the highest titer of $(R)$ - AC was achieved at $37^{\circ} \mathrm{C}$ and this temperature was found to be the most desirable for cell growth as well (data not shown). The formation of AC by decarboxylation of $\alpha$-acetolactate is an oxidative reaction (Windhorst and Gescher 2019), hence the biosynthesis of AC requires a high level of dissolved oxygen. The generation of 2,3-BD from $\mathrm{AC}$ was a reduction reaction (Zhao et al., 2015), therefore a high level of dissolved oxygen in fermentation broth would be beneficial to efficient production of AC while inhibiting the synthesis of 2,3-BD. The fermentation volume and rotation speed influenced the dissolved oxygen in shake flasks. The optimal fermentation volume and rotation speed were found to be $40 \mathrm{ml}$ and $250 \mathrm{rpm}$, respectively, and resulted in the $\mathrm{AC}$ production at $53.83 \mathrm{~g} / \mathrm{L}$.

\subsection{Optimization of Fermentation Condition in 1-L Fermenter}

A multiple parallel fermentation system with a 1-L working volume was employed to optimize the initial $\mathrm{pH}(5.5,6.0,6.5$, 7.0 and 7.5$)$, aeration rate $(0.5,0.75,1.0,1.25$ and $1.5 \mathrm{vvm})$ and agitation speed (400, 450, 500, 500, 550 and $600 \mathrm{rpm})$ for $(R)$-AC fermentation by GXASR 11 at $37^{\circ} \mathrm{C}$ with a $10 \%$ inoculation. Samples were withdrawn at intervals for the determination of residual glucose and $(R)$-AC. The fermentation ceased when the 

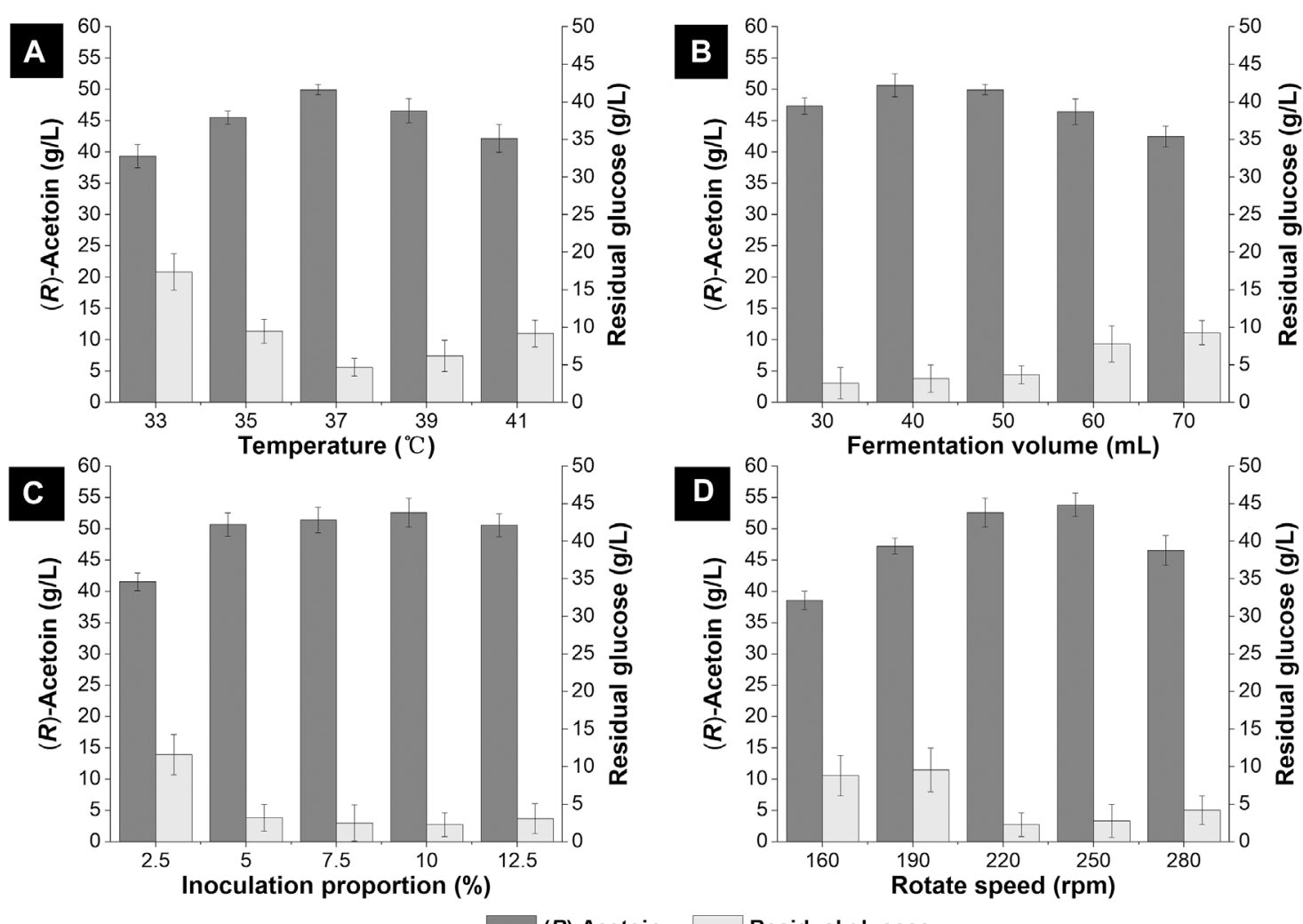

$(R)$-Acetoin

Residual glucose

FIGURE 4 | Optimization of the fermentation condition in $250 \mathrm{ml}$ shake flasks. (A) temperature $\left(33-41^{\circ} \mathrm{C}\right)$ (B) fermentation volume (30-70 ml) (C) inoculation proportion (2.5-12.5\% v/v) (D) rotate speed (160-280 rpm).

residual glucose declined below $5 \mathrm{~g} / \mathrm{L}$. Figures $\mathbf{5 A}, \mathbf{B}$ showed that the most rapid glucose consumption took place at $\mathrm{pH} 6.5$ with a maximum production of $(R)-\mathrm{AC}$ at $41.63 \mathrm{~g} / \mathrm{L}$. According to the study of Stormer (1968), under slightly acidic condition, the $\alpha$-acetolactate synthase, which is the key enzyme for synthesis of $(R)$-AC, exhibited higher enzymatic activities and resulted in the accumulation of pyruvic acid. Meanwhile, the activity of lactate dehydrogenase was relatively low, consequently leading to higher amount of pyruvate converted to AC. This observation was consistent with the optimum initial $\mathrm{pH}$ reported by previous studies (Dai et al., 2017; Jia et al., 2017b). Moreover, oxygen supply strongly affected the fermentation process of AC (Zhang et al., 2012). According to Figures 5C,D, the glucose consumption, $\mathrm{OD}_{600}$ (data not shown) and $(R)$-AC production were all relatively low with an airflow between 0.5 and $0.75 \mathrm{vvm}$, suggesting that the dissolved oxygen was insufficient for cell growth. The glucose consumption and $(R)$-AC production escalated with increasing ventilation. The highest output of $(R)$-AC $(43.18 \mathrm{~g} / \mathrm{L})$ and reasonably low by-product content were obtained at $1.0 \mathrm{vvm}$ (data not shown), thus this aeration rate was chosen as the most desirable one. This result is similar to that of a previous study (Xu et al., 2018). The agitation speed of a fermenter not only significantly affected the oxygen level in the fermentation broth, but also the mass transfer efficiency. The $(R)$ AC production and glucose consumption were relatively low when operated at 400 and $450 \mathrm{rpm}$, suggesting that the efficiency of mass transfer and oxygen supply were insufficient. The glucose consumption at 550 and $600 \mathrm{rpm}$ was close to that at $500 \mathrm{rpm}$. However, the more oxygen dissolved, the more by-products (e.g., organic acids and alcohols) were produced, which in turn reduced the AC production. Taken together, the agitation speed at $500 \mathrm{rpm}$ was the most desirable for fermentation. As seen in Figures 5B,D and $\mathrm{F}$ and Table 4, the production of $(R)-\mathrm{AC}$ in 1-L fermenter was lower than that in the shake flasks. This was mainly because of a higher level of dissolved oxygen and better mass transfer in shake flasks which led to better cell growth (data not shown) and more glucose consumption.

\subsection{Fed-Batch Fermentation}

To boost the production level of $(R)$-AC, the fed-batch fermentation was carried out in a 5-L fermenter with $2.5 \mathrm{~L}$ non-food medium. Optimizations of feeding time, concentration and constituents of feeding solution, and feeding rate were carried out for $(R)$-AC production in preliminary experiments (data not shown). The non-food medium contained an initial glucose concentration of $110 \mathrm{~g} / \mathrm{L}$ and an initial nitrogen concentration of $4.5 \mathrm{~g} / \mathrm{L}$. A feeding process was performed when the residual glucose dropped to $40 \mathrm{~g} / \mathrm{L}$. The feeding solution containing $800 \mathrm{~g} / \mathrm{L}$ glucose and $10 \mathrm{~g} / \mathrm{L}$ nitrogen source was added just once. After the feeding process, the 

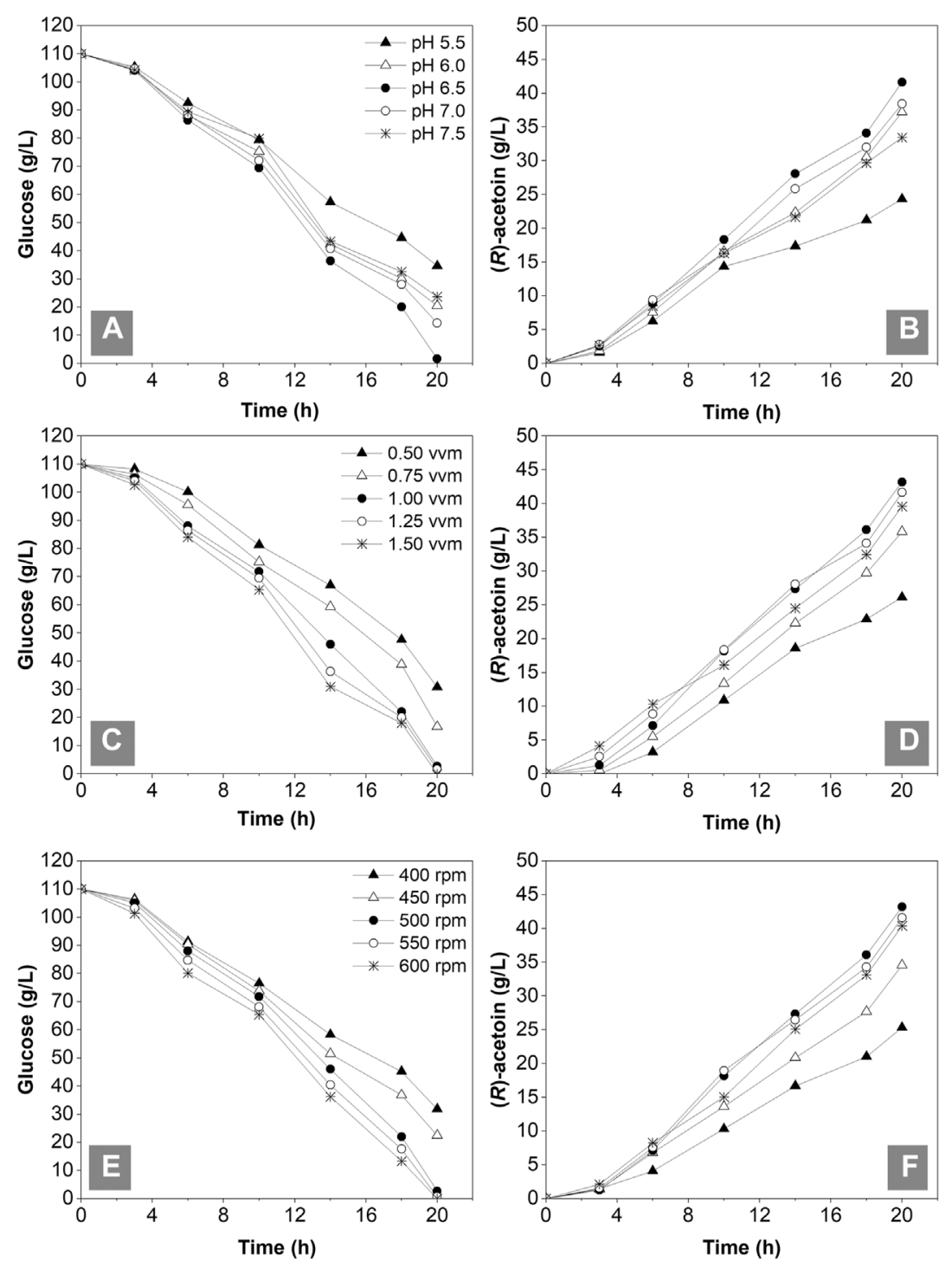

FIGURE 5 | Optimization of initial pH, aeration rates and agitation speed in the 1-L fermenter with an initial broth volume of $0.5 \mathrm{~L}$. (A) and (B) glucose consumption and $(R)$-AC production under different initial $\mathrm{pH}$ from 5.5 to 7.5 (C) and (D) glucose consumption and $(R)$-AC production under different aeration rates conditions from 0.50-1.50 vvm (E) and (F) glucose consumption and $(R)$-AC production under different agitation speed conditions from 400 to 600 rpm.

concentration of glucose reached about $140 \mathrm{~g} / \mathrm{L}$ and the fermentation was not ceased until glucose was completely consumed. As seen in Figure 6, the production of $(R)-\mathrm{AC}$ peaked at $86.04 \mathrm{~g} / \mathrm{L}$ after $48 \mathrm{~h}$, then began to decrease while the concentrations of by-products kept increasing. The strategies of fed-batch fermentation or interim feeding were also adopted by other studies with $55.3 \mathrm{~g} / \mathrm{L}$ and $60.3 \mathrm{~g} / \mathrm{L}$ productions of AC, respectively (Zhang et al., 2012; Xu et al., 2015).

Several factors could cause the impairment of $(R)-\mathrm{AC}$ production: 1) in the later stage of fermentation, the catabolism surpassed the anabolism of $(R)$-AC due to the toxicity of accumulated $(R)$-AC to cells (Hosaka et al., 1999; Huang et al., 1999), resulting in a decline of (R)-AC concentration; 2) the synthesis of other secondary metabolites, for instance, 2,3-BD, acetate and ethanol, were enhanced; 3) when the carbon and nitrogen sources were insufficient or depleted, $(R)$-AC excreted into the fermentation broth would be catabolized by active cells as the carbon source (Xiao and Xu 2007). Although many previous studies regarding biosynthesis of $(R)$-AC by engineered microorganisms have been reported, a limited number of studies so far were associated with the AC toxicity and microbial resistance against AC (Luo et al., 2014; Li et al., 2015b; Yuan et al., 2019). The mechanism of AC catabolism was only mentioned in several AC-producing Bacillus strains (Xiao and Xu 2007), such as B. subtilis (Ould Ali et al., 2001), B. licheniformis (Thanh et al., 2010) and B. thuringiensis (Peng et al., 2020b). Therefore, in addition to the optimization of the 


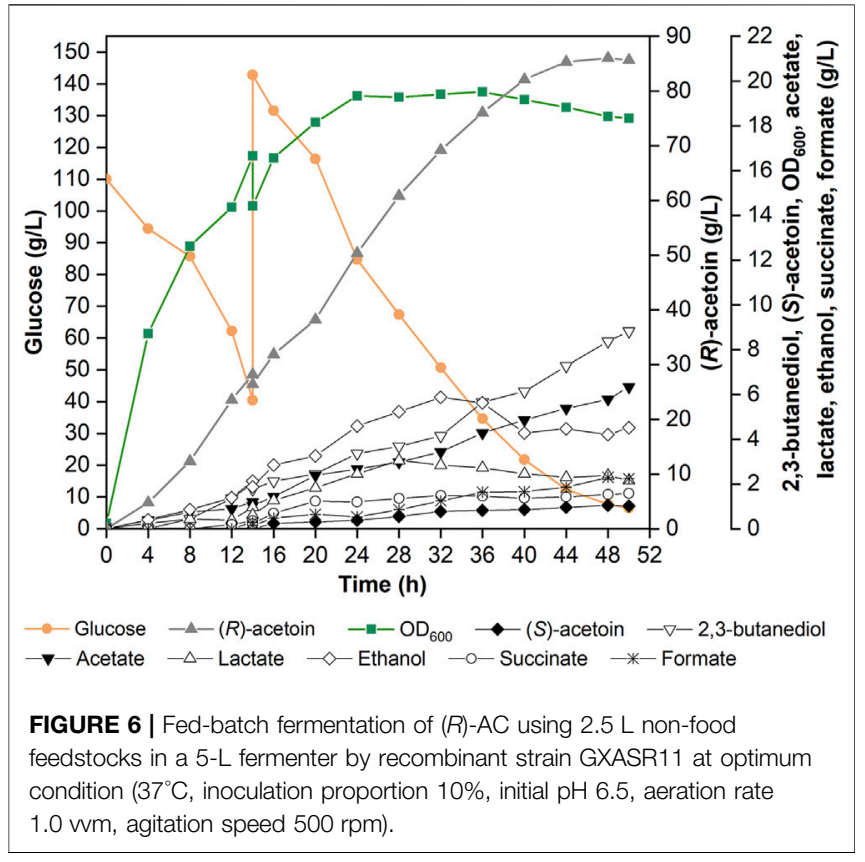

biosynthesis pathway for (R)-AC production in $E$. coli, the improvement of $(R)$-AC tolerance and the inhibition of its degradation pathways would also be investigated in future research and application.

\subsection{Condition Optimization of 2,3,5,6-Tetramethylpyrazine Production}

The formation of TMP from $2 \mathrm{~mol}$ of AC and $2 \mathrm{~mol}$ of ammonium is a spontaneous nonenzymatic reaction and is highly influenced by reaction temperature (Xiao et al., 2014; Peng et al., 2020a). It has been observed in many studies that TMP could be spontaneously formed from $\mathrm{AC}$ and ammonia salts in water solutions at a slow speed under mild conditions (Besson et al., 1997; Xiao et al., 2018). Noteworthily, the reaction process could be accelerated at elevated temperature (Zhu and Xu 2010a; Xiao et al., 2014). In this study, TMP was synthesized at $180^{\circ} \mathrm{C}$ to achieve a desirable synthesis efficiency and avoid the accumulation of potential by-products. The precursor AC was enriched in the bio-based stage, for which the optimal fermentation conditions for recombinant $E$. coli were determined. In the next stage, the most suitable ammonium salt (DAP) was mixed with fermentation broth for TMP production in a high-pressure microreactor with temperature control. As shown in Table 6, the effects of the molar ratio of AC/DAP, reaction time, temperature and rotation speed of the microreactor on the conversion rate of TMP were investigated respectively. When the reaction was carried out at $90^{\circ} \mathrm{C}$ and $200 \mathrm{rpm}$ for $2 \mathrm{~h}$ with an initial $\mathrm{pH}$ of 6.5 at different ratios of precursors $(2: 5,2.5: 5,3: 5,3.5: 5$ and 4 : 5), the optimum molar ratio of AC/DAP was obtained as 2.5:5 with a maximum conversion rate at $54.20 \%$. The amount of supplemented DAP for higher TMP production was previously investigated (Xiao et al., 2014). It was found that the TMP concentration rose as the AC/ammonium ratio increased from $1 / 1.0$ to $1 / 2.5$, however, further DAP addition could hardly improve the production. The optimal
TABLE 6 | Optimization of conditions for TMP production (mean \pm SD) in microreactor.

\begin{tabular}{|c|c|c|}
\hline Reaction parameters & $\begin{array}{l}\text { Production } \\
\text { of TMP ( } g / L)\end{array}$ & Conversion rate $(\%)$ \\
\hline \multicolumn{3}{|l|}{ Molar concentration ratio } \\
\hline $2: 5$ & $33.72 \pm 1.43$ & $50.72 \pm 2.15$ \\
\hline $2.5: 5$ & $36.04 \pm 0.74$ & $54.20 \pm 1.11$ \\
\hline $3: 5$ & $33.79 \pm 0.78$ & $50.81 \pm 1.17$ \\
\hline $3.5: 5$ & $33.46 \pm 0.14$ & $50.32 \pm 0.22$ \\
\hline $4: 5$ & $29.99 \pm 1.01$ & $45.10 \pm 1.52$ \\
\hline \multicolumn{3}{|l|}{ Time (h) } \\
\hline 1 & $33.19 \pm 0.07$ & $49.91 \pm 0.10$ \\
\hline 2 & $36.04 \pm 0.74$ & $54.20 \pm 1.11$ \\
\hline 3 & $36.67 \pm 0.56$ & $55.15 \pm 0.84$ \\
\hline 4 & $32.58 \pm 0.41$ & $48.99 \pm 0.62$ \\
\hline 5 & $30.77 \pm 0.18$ & $46.27 \pm 0.27$ \\
\hline \multicolumn{3}{|l|}{ Temperature $\left({ }^{\circ} \mathrm{C}\right)$} \\
\hline 90 & $36.67 \pm 0.56$ & $55.15 \pm 0.84$ \\
\hline 120 & $37.46 \pm 1.25$ & $56.33 \pm 1.88$ \\
\hline 150 & $40.58 \pm 2.02$ & $61.03 \pm 3.04$ \\
\hline 180 & $45.64 \pm 1.61$ & $68.64 \pm 2.42$ \\
\hline 210 & $42.06 \pm 0.34$ & $63.25 \pm 0.51$ \\
\hline \multicolumn{3}{|l|}{ Rotation speed (rpm) } \\
\hline 200 & $45.64 \pm 1.61$ & $68.64 \pm 2.42$ \\
\hline 400 & $46.48 \pm 0.38$ & $69.90 \pm 0.57$ \\
\hline 600 & $44.17 \pm 0.77$ & $66.43 \pm 1.16$ \\
\hline 800 & $42.77 \pm 0.48$ & $64.32 \pm 0.73$ \\
\hline 1,200 & $40.23 \pm 0.34$ & $60.50 \pm 0.51$ \\
\hline
\end{tabular}

SD, standard deviation, $n=3$.

reaction time was identified as $3 \mathrm{~h}$ with a conversion rate of $55.15 \%$. Along with the elevation of reaction temperature, the TMP production gradually increased. The most suitable reaction temperature was determined as $180^{\circ} \mathrm{C}$ and the corresponding TMP production was $45.64 \mathrm{~g} / \mathrm{L}$ with a conversion rate of $68.64 \%$. The elevated temperature could not only accelerate the formation of TMP in the condensation reaction (Kim et al., 1994), but also cease the further degradation of AC caused by microbial enzymes. Besides, the temperature at $180^{\circ} \mathrm{C}$ facilitated to minimize the risk of biological pathogenic factors from fermentation (Xiao et al., 2014). Finally, the optimal rotation speed was determined as $400 \mathrm{rpm}$ with an optimal conversion rate of $69.9 \%$.

Based on the optimal conditions for TMP conversion (AC/DAP ratio $=2.5: 5$, reaction time $=3 \mathrm{~h}$, temperature $=180^{\circ} \mathrm{C}$ and ration speed $=400 \mathrm{rpm}$ ), the effect of initial $\mathrm{pH}$ on the condensation of TMP was investigated. The $\mathrm{pH}$ of fermentation broth was adjusted by phosphoric acid and ammonia solution to 6.0, 6.5, 7.0, 7.5 and 8.0, respectively. The TMP production was determined by GC and the conversion rate was calculated. The results (Figure 7) showed that both the titer and conversion rate of TMP increased with an elevation in $\mathrm{pH}$. The production of TMP peaked at $56.72 \mathrm{~g} / \mathrm{L}$ at $\mathrm{pH} 7.5$ with a corresponding conversion rate of $85.30 \%$. According to previous reports, the initial $\mathrm{pH}$ of fermentation broth towards neutrality or weak alkalinity would be more beneficial for TMP production (Xiao et al., 2006; Zhu and Xu 2010b; Zhu et al., 2010; Zhang et al., 2019). Our observation was consistent with the $\mathrm{pH}$ choice at 7.5 from another report (Xu et al., 2018). As the $\mathrm{pH}$ increased to 8.0, the titer of TMP began to decline. This was presumably due to the hindrance of surplus $\mathrm{NH}_{4}^{+}$and the 


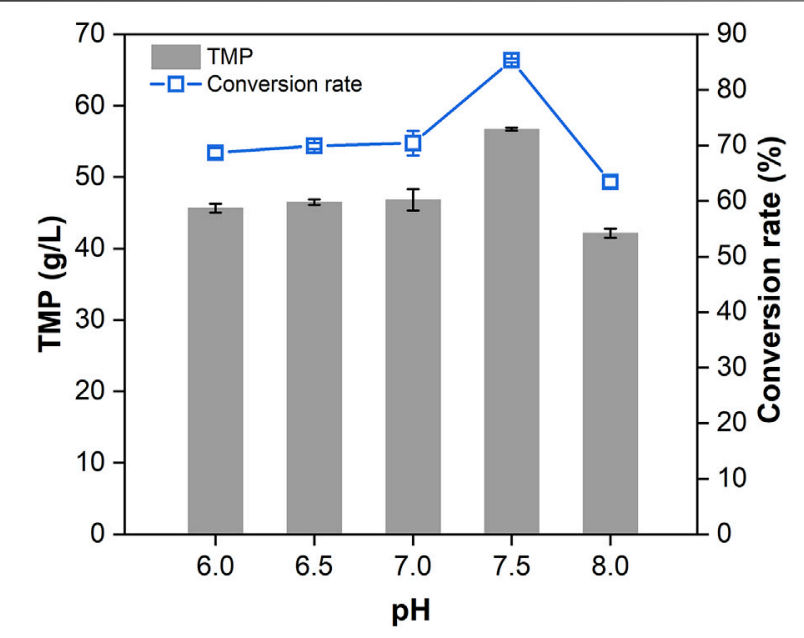

FIGURE 7 | Effect of initial pH (6.0-8.0) on the production of TMP. Error bars represent the standard deviations.

detailed reasons should be further investigated. Although TMP could be efficiently produced from $\mathrm{AC}$ and DAP in a high-pressure microreactor without loss caused by sublimation, the pigments in TMP resulting from the Maillard reaction would complicate the subsequent processing. Thus, effective decolorization methods are required to be exploited for acquiring pure TMP crystal in future work.

\section{CONCLUSION}

Low cost and green technologies to produce valuable TMP are urgently required to meet the increasing market demand. We have addressed this by construction and optimization of $E$. coli cell factories for high-yield production of $(R)$-AC, and $86.04 \mathrm{~g} / \mathrm{L}(R)$ AC was obtained using the hydrolysates of tapioca flour and cottonseed cake as cost-effective raw materials by fed-batch

\section{REFERENCES}

Abubaker, H. O., Sulieman, A. M. E., and Elamin, H. B. (2012). Utilization of Schizosaccharomyces pombe for Production of Ethanol from Cane Molasses. J. Microbiol. Res. 2, 36-40. doi:10.5923/j.microbiology.20120202.06

Adamczyk, P. A., and Reed, J. L. (2017). Escherichia coli as a Model Organism for Systems Metabolic Engineering. Curr. Opin. Syst. Biol. 6, 80-88. doi:10.1016/ j.coisb.2017.11.001

Bae, S.-J., Kim, S., Park, H. J., Kim, J., Jin, H., Kim, B.-g., et al. (2021). High-yield Production of $(R)$-acetoin in Saccharomyces cerevisiae by Deleting Genes for NAD(P)H-dependent Ketone Reductases Producing Meso-2,3-Butanediol and 2,3-dimethylglycerate. Metab. Eng. 66, 68-78. doi:10.1016/j.ymben.2021.04.001 Basso, T. O., de Kok, S., Dario, M., do Espirito-Santo, J. C. A., Müller, G., Schlölg, P. S., et al. (2011). Engineering Topology and Kinetics of Sucrose Metabolism in Saccharomyces cerevisiae for Improved Ethanol Yield. Metab. Eng. 13 (6), 694-703. doi:10.1016/j.ymben.2011.09.005

Besson, I., Creuly, C., Gros, J. B., and Larroche, C. (1997). Pyrazine Production by Bacillus Subtilis in Solid-State Fermentation on Soybeans. Appl. Microbiol. Biotechnol. 47 (5), 489-495. doi:10.1007/s002530050961 fermentation. Subsequently, 56.72 g/L TMP was obtained from DAP and biosynthesized (R)-AC in a $20 \mathrm{ml}$ high-pressure microreactor system with a substrate conversion rate of $85.30 \%$. Collectively, this study demonstrated the feasibility that obtaining high-level $(R)$-AC with high optical purity by metabolic engineering and fermentation engineering technology and provided an efficient and sustainable approach for synthesizing high-value TMP via using low-cost biomass feedstocks, making it more economically viable for a scale-up. Further studies will focus on hydrolyzation process optimization, strain engineering for $(R)$-AC resistance and subsequent processing for separation and decolorization of TMP.

\section{DATA AVAILABILITY STATEMENT}

The original contributions presented in the study are included in the article/Supplementary Material, further inquiries can be directed to the corresponding authors.

\section{AUTHOR CONTRIBUTIONS}

$\mathrm{XC}, \mathrm{MD}$, and JLu conceived and designed the experiments. JLi, $\mathrm{ZM}$, and $\mathrm{XC}$ conducted most of the experiments. XC, $\mathrm{ZM}, \mathrm{MD}$, and NX analyzed the data. MD and XC wrote the manuscript. All authors made contributions to the final manuscript.

\section{FUNDING}

This work was supported by the National Natural Science Foundation of China (21868007 and 21466007), Science and Technology Service Network Initiative of Chinese Academy of Sciences (KFJ-STS-QYZD-201), Fundamental Research Funds for Guangxi Academy of Sciences (2020YBJ703, 2020YBJ702, 2021YFJ1210 and 2019YJJ1007) and Natural Science Foundation of Guangxi Province (2018GXNSFBA281017, 2021GXNSFBA196087 and 2021GXNSFBA220015).

Braña, A. F., Rodríguez, M., Pahari, P., Rohr, J., García, L. A., and Blanco, G. (2014). Activation and Silencing of Secondary Metabolites in Streptomyces Albus and Streptomyces Lividans after Transformation with Cosmids Containing the Thienamycin Gene Cluster from Streptomyces Cattleya. Arch. Microbiol. 196 (5), 345-355. doi:10.1007/s00203-014-0977-Z

Cao, J., Miao, Q., Miao, S., Bi, L., Zhang, S., Yang, Q., et al. (2015). Tetramethylpyrazine (TMP) Exerts Antitumor Effects by Inducing Apoptosis and Autophagy in Hepatocellular Carcinoma. Int. Immunopharmacology 26 (1), 212-220. doi:10.1016/j.intimp.2015.03.028

Celińska, E., and Grajek, W. (2009). Biotechnological Production of 2,3Butanediol-Current State and Prospects. Biotechnol. Adv. 27 (6), 715-725. doi:10.1016/j.biotechadv.2009.05.002

Chen, G., and Zhang, B. (2012). Hydrolysis of Granular Corn Starch with Controlled Pore Size. J. Cereal Sci. 56 (2), 316-320. doi:10.1016/j.jcs.2012.01.011

Chen, Z., Zhang, C., Gao, F., Fu, Q., Fu, C., He, Y., et al. (2018). A Systematic Review on the Rhizome of Ligusticum Chuanxiong Hort. (Chuanxiong). Food Chem. Toxicol. 119, 309-325. doi:10.1016/j.fct.2018.02.050

Couto, M. R., Rodrigues, J. L., and Rodrigues, L. R. (2017). Optimization of Fermentation Conditions for the Production of Curcumin by Engineered Escherichia coli. J. R. Soc. Interf. 14 (133), 20170470. doi:10.1098/rsif.2017.0470 
Cui, D.-Y., Wei, Y.-N., Lin, L.-C., Chen, S.-J., Feng, P.-P., Xiao, D.-G., et al. (2020). Increasing Yield of 2,3,5,6-Tetramethylpyrazine in Baijiu through Saccharomyces cerevisiae Metabolic Engineering. Front. Microbiol. 11. doi:10.3389/fmicb.2020.596306

Dai, J.-Y., Ma, L.-H., Wang, Z.-F., Guan, W.-T., and Xiu, Z.-L. (2017). Sugaring-out Extraction of Acetoin from Fermentation Broth by Coupling with Fermentation. Bioproc. Biosyst. Eng. 40 (3), 423-429. doi:10.1007/s00449-016-1710-x

Demain, A. L., Jackson, M., and Trenner, N. R. (1967). Thiamine-dependent Accumulation of Tetramethylpyrazine Accompanying a Mutation in the Isoleucine-Valine Pathway. J. Bacteriol. 94 (2), 323-326. doi:10.1128/ jb.94.2.323-326.1967

Dickschat, J. S., Reichenbach, H., Wagner-Döbler, I., and Schulz, S. (2005). Novel Pyrazines from the Myxobacterium Chondromyces crocatus and Marine Bacteria. Eur. J. Org. Chem. 2005 (19), 4141-4153. doi:10.1002/ejoc.200500280

Dickschat, J. S., Wickel, S., Bolten, C. J., Nawrath, T., Schulz, S., and Wittmann, C. (2010). Pyrazine Biosynthesis in Corynebacterium Glutamicum. Eur. J. Org. Chem. 2010 (14), 2687-2695. doi:10.1002/ejoc.201000155

Förster, A. H., Beblawy, S., Golitsch, F., and Gescher, J. (2017). Electrode-assisted Acetoin Production in a Metabolically Engineered Escherichia coli Strain. Biotechnol. Biofuels 10 (1), 65. doi:10.1186/s13068-017-0745-9

Guo, M., Liu, Y., and Shi, D. (2016). Cardiovascular Actions and Therapeutic Potential of Tetramethylpyrazine (Active Component Isolated from Rhizoma Chuanxiong): Roles and Mechanisms. Biomed. Res. Int. 2016, 1-9. doi:10.1155/ 2016/2430329

Guo, Z., Zhao, X., He, Y., Yang, T., Gao, H., Li, G., et al. (2017). Efficient (3R)Acetoin Production from Meso-2,3-Butanediol Using a New Whole-Cell Biocatalyst with Co-expression of Meso-2,3-Butanediol Dehydrogenase, NADH Oxidase, and Vitreoscilla Hemoglobin. J. Microbiol. Biotechnol. 27 (1), 92-100. doi:10.4014/jmb.1608.08063

Hao, F., Wu, Q., and Xu, Y. (2013). Precursor Supply Strategy for Tetramethylpyrazine Production by Bacillus subtilis on Solid-State Fermentation of Wheat Bran. Appl. Biochem. Biotechnol. 169 (4), 1346-1352. doi:10.1007/s12010-012-0083-0

Hao, Y., Wang, Z., Zou, Y., He, R., Ju, X., and Yuan, J. (2020). Effect of Static-state Fermentation on Volatile Composition in Rapeseed Meal. J. Sci. Food Agric. 100 (5), 2145-2152. doi:10.1002/jsfa.10238

Hosaka, T., Ui, S., and Mimura, A. (1999). Separation and Properties of Two Acetylacetoin Reductases from Bacillus cereus YUF-4. Biosci. Biotechnol. Biochem. 63 (1), 199-201. doi:10.1271/bbb.63.199

Huang, M., Oppermann-Sanio, F. B., and Steinbüchel, A. (1999). Biochemical and Molecular Characterization of the Bacillus subtilis Acetoin Catabolic Pathway. J. Bacteriol. 181 (12), 3837-3841. doi:10.1128/JB.181.12.3837-3841.1999

Huang, Z., Xiao, H., and Yi, J. (2011). HPLC Determination of Tetramethylpyrazine in Geo-Authentic Ligusticum Chuanxiong Hort. of Sichuan Province. Chin. J. Pharm. Anal. 31 (1), 103-106. doi:10.16155/ j.0254-1793.2017.01.01

Jang, J.-W., Jung, H.-M., Im, D.-K., Jung, M.-Y., and Oh, M.-K. (2017). Pathway Engineering of Enterobacter aerogenes to Improve Acetoin Production by Reducing By-Products Formation. Enzyme Microb. Tech. 106, 114-118. doi:10.1016/j.enzmictec.2017.07.009

Ji, X.-J., Huang, H., and Ouyang, P.-K. (2011). Microbial 2,3-butanediol Production: A State-Of-The-Art Review. Biotechnol. Adv. 29 (3), 351-364. doi:10.1016/j.biotechadv.2011.01.007

Jia, R.-B., Guo, W.-L., Zhou, W.-B., Jiang, Y.-J., Zhu, F.-F., Chen, J.-H., et al. (2017a). Screening and Identification of Monacus strain with High TMP Production and Statistical Optimization of its Culture Medium Composition and Liquid State Fermentation Conditions Using Response Surface Methodology (RSM). Biotechnol. Biotechnological Equipment 31 (4), 1-11. doi:10.1080/13102818.2017.1335176

Jia, X., Peng, X., Liu, Y., and Han, Y. (2017b). Conversion of Cellulose and Hemicellulose of Biomass Simultaneously to Acetoin by Thermophilic Simultaneous Saccharification and Fermentation. Biotechnol. Biofuels 10 (1), 232. doi:10.1186/s13068-017-0924-8

Kim, K., Lee, H., Shon, D., and Chung, D. (1994). Optimum Conditions for the Production of Tetramethylpyrazine Flavor Compound by Aerobic Fed-Batch Culture of Lactococcus lactis subsp. lactis biovar. diacetylactis FC1. J. Microbiol. Biotechn 4 (4), 327-332. Available online at: https:// www.jmb.or.kr/journal/view.html? uid=200\&vmd=Full\#articles-tool.
Larroche, C., Besson, I., and Gros, J.-B. (1999). High Pyrazine Production by Bacillus subtilis in Solid Substrate Fermentation on Ground Soybeans. Process. Biochem. 34 (6), 667-674. doi:10.1016/S0032-9592(98)00141-1

Lévêque, E., Janeček, Š., Haye, B., and Belarbi, A. (2000). Thermophilic Archaeal Amylolytic Enzymes. Enzyme Microb. Tech. 26 (1), 3-14. doi:10.1016/S01410229(99)00142-8

Li, J.-X., Huang, Y.-Y., Chen, X.-R., Du, Q.-S., Meng, J.-Z., Xie, N.-Z., et al. (2018). Enhanced Production of Optical (S)-acetoin by a Recombinant Escherichia coli Whole-Cell Biocatalyst with NADH Regeneration. RSC Adv. 8 (53), 30512-30519. doi:10.1039/C8RA06260A

Li, L., Li, K., Wang, Y., Chen, C., Xu, Y., Zhang, L., et al. (2015a). Metabolic Engineering of Enterobacter cloacae for High-Yield Production of Enantiopure (2 R ,3 R )-2,3-butanediol from Lignocellulose-Derived Sugars. Metab. Eng. 28, 19-27. doi:10.1016/j.ymben.2014.11.010

Li, S., Liu, L., and Chen, J. (2015b). Mitochondrial Fusion and Fission Are Involved in Stress Tolerance of Candida glabrata. Bioresour. Bioproc. 2 (1), 1-9. doi:10.1186/s40643-015-0041-0

Liu, Q. (2002). A Study of Enzymatic Hydrolysis of Starch in Potato Pulp. J. Food Sci. 67 (6), 2113-2117. doi:10.1111/j.1365-2621.2002.tb09510.x

Lu, L., Mao, Y., Kou, M., Cui, Z., Jin, B., Chang, Z., et al. (2020). Engineering central Pathways for Industrial-Level (3R)-Acetoin Biosynthesis in Corynebacterium glutamicum. Microb. Cel Fact 19, 1-16. doi:10.1186/s12934-020-01363-8

Luo, Q., Wu, J., and Wu, M. (2014). Enhanced Acetoin Production by Bacillus amyloliquefaciens through Improved Acetoin Tolerance. Process Biochem. 49 (8), 1223-1230. doi:10.1016/j.procbio.2014.05.005

Meng, W., Ding, F., Wang, R.-M., and Wang, T.-F. (2020). Enhanced Production of Tetramethylpyrazine in Bacillus licheniformis BL1 through aldC Overexpression and Acetaldehyde Supplementation. Sci. Rep. 10 (1), 3544. doi:10.1038/s41598-020-60345-3

Meng, W., Wang, R., and Xiao, D. (2015). Metabolic Engineering of Bacillus subtilis to Enhance the Production of Tetramethylpyrazine. Biotechnol. Lett. 37 (12), 2475-2480. doi:10.1007/s10529-015-1950-x

Meng, W., Xiao, D., and Wang, R. (2016). Enhanced Production of Tetramethylpyrazine in Bacillus licheniformis BL1 by bdhA Disruption and 2,3-butanediol Supplementation. World J. Microbiol. Biotechnol. 32 (3), 46-52. doi:10.1007/s11274-015-1992-1

Mohamed, E. T., Mundhada, H., Landberg, J., Cann, I., Mackie, R. I., Nielsen, A. T., et al. (2019). Generation of an E. coli Platform Strain for Improved Sucrose Utilization Using Adaptive Laboratory Evolution. Microb. Cel Fact 18 (1), 116. doi:10.1186/s12934-019-1165-2

Müller, R., and Rappert, S. (2010). Pyrazines: Occurrence, Formation and Biodegradation. Appl. Microbiol. Biotechnol. 85 (5), 1315-1320. doi:10.1007/ s00253-009-2362-4

Nadal, I., Rico, J., Pérez-Martínez, G., Yebra, M. J., and Monedero, V. (2009). Diacetyl and Acetoin Production from Whey Permeate Using Engineered Lactobacillus casei. J. Ind. Microbiol. Biotechnol. 36 (9), 1233-1237. doi:10.1007/s10295-009-0617-9

Ould Ali, N., Bignon, J., Rapoport, G., and Debarbouille, M. (2001). Regulation of the Acetoin Catabolic Pathway Is Controlled by Sigma L in Bacillus subtilis. J. Bacteriol. 183 (8), 2497-2504. doi:10.1128/JB.183.8.2497-2504.2001

Peng, K., Guo, D., Lou, Q., Lu, X., Cheng, J., Qiao, J., et al. (2020a). Synthesis of Ligustrazine from Acetaldehyde by a Combined Biological-Chemical Approach. ACS Synth. Biol. 9 (11), 2902-2908. doi:10.1021/ acssynbio.0c00113

Peng, Q., Zhao, X., Wen, J., Huang, M., Zhang, J., and Song, F. (2020b). Transcription in the Acetoin Catabolic Pathway Is Regulated by AcoR and CcpA in Bacillus thuringiensis. Microbiol. Res. 235, 126438. doi:10.1016/ j.micres.2020.126438

Reid, S. J., and Abratt, V. R. (2005). Sucrose Utilisation in Bacteria: Genetic Organisation and Regulation. Appl. Microbiol. Biotechnol. 67 (3), 312-321. doi:10.1007/s00253-004-1885-y

Romano, P., and Suzzi, G. (1996). Origin and Production of Acetoin during Wine Yeast Fermentation. Appl. Environ. Microbiol. 62 (2), 309-315. doi:10.1128/ aem.62.2.309-315.1996

Ruiz, M. I., Sanchez, C. I., Torrres, R. G., and Molina, D. R. (2011). Enzymatic Hydrolysis of Cassava Starch for Production of Bioethanol with a Colombian Wild Yeast Strain. J. Braz. Chem. Soc. 22, 2337-2343. doi:10.1590/S010350532011001200014 
Störmer, F. C. (1968). The pH 6 Acetolactate-Forming Enzyme from Aerobacter aerogenes. J. Biol. Chem. 243 (13), 3735-3739. doi:10.1016/S0021-9258(19)34199-7

Su, H.-H., Xu, R.-Y., Yang, Z.-D., Guo, Y.-S., Gao, J.-Y., Mo, L.-Z., et al. (2021). Green Synthesis of Isomaltulose from Cane Molasses by an Immobilized Recombinant Escherichia coli Strain and its Prebiotic Activity. LWT 143, 111054. doi:10.1016/j.lwt.2021.111054

Sun, J.-A., Zhang, L.-Y., Rao, B., Shen, Y.-L., and Wei, D.-Z. (2012). Enhanced Acetoin Production by Serratia marcescens H32 with Expression of a WaterForming NADH Oxidase. Bioresour. Tech. 119, 94-98. doi:10.1016/ j.biortech.2012.05.108

Thanh, T. N., Jürgen, B., Bauch, M., Liebeke, M., Lalk, M., Ehrenreich, A., et al. (2010). Regulation of Acetoin and 2,3-butanediol Utilization in Bacillus licheniformis. Appl. Microbiol. Biotechnol. 87 (6), 2227-2235. doi:10.1007/ s00253-010-2681-5

Vivijs, B., Moons, P., Aertsen, A., Michiels, C. W., and Elkins, C. A. (2014). Acetoin Synthesis Acquisition Favors Escherichia coli Growth at Low pH. Appl. Environ. Microbiol. 80 (19), 6054-6061. doi:10.1128/AEM.01711-14

Wen, A., Xie, C., Mazhar, M., Wang, C., Zeng, H., Qin, L., et al. (2020). Tetramethylpyrazine from Adlay (Coix lacryma-jobi) Biotransformation by Bacillus subtilis and its Quality Characteristics. J. Food Sci. Technol. 57 (11), 4092-4102. doi:10.1007/s13197-020-04443-0

Windhorst, C., and Gescher, J. (2019). Efficient Biochemical Production of Acetoin from Carbon Dioxide Using Cupriavidus necator H16. Biotechnol. Biofuels 12 (1), 163. doi:10.1186/s13068-019-1512-x

Xiao, Z., Hou, X., Lyu, X., Xi, L., and Zhao, J.-y. (2014). Accelerated green Process of Tetramethylpyrazine Production from Glucose and Diammonium Phosphate. Biotechnol. Biofuels 7 (1), 106-108. doi:10.1186/1754-6834-7-106

Xiao, Z. J., Liu, P. H., Qin, J. Y., and Xu, P. (2007). Statistical Optimization of Medium Components for Enhanced Acetoin Production from Molasses and Soybean Meal Hydrolysate. Appl. Microbiol. Biotechnol. 74 (1), 61-68. doi:10.1007/s00253-006-0646-5

Xiao, Z. J., Xie, N. Z., Liu, P. H., Hua, D. L., and Xu, P. (2006). Tetramethylpyrazine Production from Glucose by a Newly Isolated Bacillus Mutant. Appl. Microbiol. Biotechnol. 73 (3), 512-518. doi:10.1007/s00253-006-0491-6

Xiao, Z., and Lu, J. R. (2014). Strategies for Enhancing Fermentative Production of Acetoin: a Review. Biotechnol. Adv. 32 (2), 492-503. doi:10.1016/ j.biotechadv.2014.01.002

Xiao, Z., Lv, C., Gao, C., Qin, J., Ma, C., Liu, Z., et al. (2010). A Novel Whole-Cell Biocatalyst with $\mathrm{NAD}^{+}$Regeneration for Production of Chiral Chemicals. PLOS ONE 5 (1), e8860. doi:10.1371/journal.pone.0008860

Xiao, Z., and Xu, P. (2007). Acetoin Metabolism in Bacteria. Crit. Rev. Microbiol. 33 (2), 127-140. doi:10.1080/10408410701364604

Xiao, Z., Zhao, L., Tian, L., Wang, L., and Zhao, J.-y. (2018). GC-FID Determination of Tetramethylpyrazine and Acetoin in Vinegars and Quantifying the Dependence of Tetramethylpyrazine on Acetoin and Ammonium. Food Chem. 239, 726-732. doi:10.1016/j.foodchem.2017.07.015

Xu, Q., Xie, L., Li, Y., Lin, H., Sun, S., Guan, X., et al. (2015). Metabolic Engineering of Escherichia Coli for Efficient Production of (3R)-Acetoin. J. Chem. Technol. Biotechnol. 90 (1), 93-100. doi:10.1002/jctb.4293

Xu, Y., Xu, C., Li, X., Sun, B., Eldin, A. A., and Jia, Y. (2018). A Combinational Optimization Method for Efficient Synthesis of Tetramethylpyrazine by the Recombinant Escherichia coli. Biochem. Eng. J. 129, 33-43. doi:10.1016/ j.bej.2017.10.010

Yamada-Onodera, K., Yamamoto, H., Kawahara, N., and Tani, Y. (2002). Expression of the Gene of Glycerol Dehydrogenase from Hansenula polymorpha Dl-1 in Escherichia coli for the Production of Chiral Compounds. Acta Biotechnol. 22 (3-4), 355-362. doi:10.1002/15213846(200207)22:3/4<355:aid-abio355>3.0.co;2-6

Yin, D. D., Yang, M., Wang, Y. L., Yin, D. K., Liu, H. K., Zhou, M., et al. (2018). High Tetramethylpyrazine Production by the Endophytic Bacterial Bacillus subtilis Isolated from the Traditional Medicinal Plant Ligusticum chuanxiong Hort. AMB Expr. 8 (1), 193-201. doi:10.1186/s13568-0180721-1

Yuan, H., Xu, Y., Chen, Y., Zhan, Y., Wei, X., Li, L., et al. (2019). Metabolomics Analysis Reveals Global Acetoin Stress Response of Bacillus licheniformis. Metabolomics 15 (3), 25. doi:10.1007/s11306-019-1492-7

Zhang, L., Chen, S., Xie, H., Tian, Y., and Hu, K. (2012). Efficient Acetoin Production by Optimization of Medium Components and Oxygen Supply Control Using a Newly isolated Paenibacillus polymyxa CS107. J. Chem. Technol. Biotechnol. 87 (11), 1551-1557. doi:10.1002/jctb.3791

Zhang, W., Si, G., Rao, Z., Li, J., Zhang, X., Mei, J., et al. (2019). High Yield of Tetramethylpyrazine in Functional Fuqu Using Bacillus amyloliquefaciens. Food Biosci. 31, 100435. doi:10.1016/j.fbio.2019.100435

Zhang, X., Yang, T.-w., Lin, Q., Xu, M.-j., Xia, H.-f., Xu, Z.-h., et al. (2011). Isolation and Identification of an Acetoin High Production Bacterium that Can Reverse Transform 2,3-butanediol to Acetoin at the Decline Phase of Fermentation. World J. Microbiol. Biotechnol. 27 (12), 2785-2790. doi:10.1007/s11274-011$0754-y$

Zhang, X., Zhang, R., Bao, T., Rao, Z., Yang, T., Xu, M., et al. (2014). The Rebalanced Pathway Significantly Enhances Acetoin Production by Disruption of Acetoin Reductase Gene and Moderate-Expression of a New Water-Forming NADH Oxidase in Bacillus subtilis. Metab. Eng. 23, 34-41. doi:10.1016/j.ymben.2014.02.002

Zhao, X., Zhang, X., Rao, Z., Bao, T., Li, X., Xu, M., et al. (2015). Identification and Characterization of a Novel 2,3-butanediol Dehydrogenase/acetoin Reductase from Corynebacterium crenatum SYPA5-5. Lett. Appl. Microbiol. 61 (6), 573-579. doi:10.1111/lam.12495

Zhong, H., Shen, J., Meng, Z., Zhao, J.-y., and Xiao, Z. (2020a). Tetramethylpyrazine Production from Edible Materials by the Probiotic Bacillus coagulans. Prep. Biochem. Biotechnol. 50 (9), 935-942. doi:10.1080/ 10826068.2020.1774777

Zhong, H., Wang, L., Zhao, J.-y., and Xiao, Z. (2020b). Fermentative Production of Chiral Acetoin by Wild-type Bacillus Strains. Prep. Biochem. Biotechnol. 50 (2), 116-122. doi:10.1080/10826068.2019.1666280

Zhu, B.-F., and Xu, Y. (2010a). A Feeding Strategy for Tetramethylpyrazine Production by Bacillus subtilis Based on the Stimulating Effect of Ammonium Phosphate. Bioproc. Biosyst. Eng. 33 (8), 953-959. doi:10.1007/ s00449-010-0419-5

Zhu, B.-F., Xu, Y., and Fan, W.-L. (2010). High-yield Fermentative Preparation of Tetramethylpyrazine by Bacillus sp. Using an Endogenous Precursor Approach. J. Ind. Microbiol. Biotechnol. 37 (2), 179-186. doi:10.1007/s10295-009-0661-5

Zhu, B.-F., and Xu, Y. (2010b). Production of Tetramethylpyrazine by Batch Culture of Bacillus subtilis with Optimal pH Control Strategy. J. Ind. Microbiol. Biotechnol. 37 (8), 815-821. doi:10.1007/s10295-010-0726-5

Conflict of Interest: The authors declare that the research was conducted in the absence of any commercial or financial relationships that could be construed as a potential conflict of interest.

Publisher's Note: All claims expressed in this article are solely those of the authors and do not necessarily represent those of their affiliated organizations, or those of the publisher, the editors and the reviewers. Any product that may be evaluated in this article, or claim that may be made by its manufacturer, is not guaranteed or endorsed by the publisher.

Copyright $\odot 2022 \mathrm{Li}, \mathrm{Lu}, \mathrm{Ma}, \mathrm{Li}$, Chen, Diao and Xie. This is an open-access article distributed under the terms of the Creative Commons Attribution License (CC BY). The use, distribution or reproduction in other forums is permitted, provided the original author(s) and the copyright owner(s) are credited and that the original publication in this journal is cited, in accordance with accepted academic practice. No use, distribution or reproduction is permitted which does not comply with these terms. 